\title{
Article \\ The Role of Maintenance Operator in Industrial Manufacturing Systems: Research Topics and Trends
}

\author{
Alessia M. R. Tortora*(D), Valentina Di Pasquale (D), Chiara Franciosi $\mathbb{D}^{\mathrm{D}}$, Salvatore Miranda $(\mathbb{D}$ and Raffaele Iannone \\ Department of Industrial Engineering, University of Salerno, I-84084 Fisciano, Italy; \\ vdipasquale@unisa.it (V.D.P.); cfranciosi@unisa.it (C.F.); smiranda@unisa.it (S.M.); riannone@unisa.it (R.I.) \\ * Correspondence: altortora@unisa.it; Tel.: +39-3481294189
}

Citation: Tortora, A.M.R.; Di

Pasquale, V.; Franciosi, C.; Miranda,

S.; Iannone, R. The Role of

Maintenance Operator in Industrial Manufacturing Systems: Research Topics and Trends. Appl. Sci. 2021, 11, 3193. https://doi.org/10.3390/ app11073193

Academic Editor: Peng-Yeng Yin

Received: 27 February 2021

Accepted: 26 March 2021

Published: 2 April 2021

Publisher's Note: MDPI stays neutral with regard to jurisdictional claims in published maps and institutional affiliations.

Copyright: (c) 2021 by the authors. Licensee MDPI, Basel, Switzerland. This article is an open access article distributed under the terms and conditions of the Creative Commons Attribution (CC BY) license (https:// creativecommons.org/licenses/by/ $4.0 /)$.

\begin{abstract}
Maintenance contributes to gaining high business performance, guarantees system availability and reliability as well as safe and sustainable operations. Maintenance activity effectiveness depends on competences and the skills of operators whose performance strongly affects maintenance and production operations. The research field of human issues in industrial maintenance was deeply addressed in the literature; however, the current industrial paradigm, which focusses on the integration of new technologies in conventional manufacturing operations to support human performance, sheds light on new challenges for enterprises and opportunities for research in this field. While some literature reviews in the field of human errors and human factors are available, no study investigated the main topics, research trends and challenges related to the role of maintenance operators in manufacturing systems. This paper addresses the current state-of-the-art role of maintenance operators in manufacturing systems, providing an overview of the main studies. A systematic literature review was carried out to identify significant papers. Then, a topic modelling algorithm was used to detect the main topics of the selected papers to provide the research trends of the subject. The identified topics provided interesting research insights on the human role in industrial maintenance. Research trends and further research opportunities were defined.
\end{abstract}

Keywords: maintenance operator; manufacturing systems; smart operator; Industry 4.0; Latent Dirichlet Allocation

\section{Introduction}

Maintenance significantly affects most of the total cost of production, from about $15 \%$ to $40 \%$ [1], production efficiency, on-time deliveries, capacity and overall cost efficiency, and product quality. Indeed, maintenance can mitigate machine deterioration in manufacturing systems and consequently improve product quality and machine reliability [2]. Therefore, maintenance contributes to gain high business performance, guarantee system availability, reliability, safety, and sustainability [3,4].

Moreover, the evolution of production processes in recent decades influenced the way maintenance was managed and new maintenance policies emerged to meet this undesirable behavior, requiring efforts from all stakeholders to guarantee the commitment [5]. Therefore, the increase in the complexity and automation of modern production systems sheds light on the relevance of reliable maintenance processes and the need for competent human resources. Human factors cannot be ignored because of the high percentage of human errors and their economic, social and safety consequences in different industrial contexts $[6,7]$. For these reasons, proper management of maintenance operators is essential.

Human issues in maintenance are studied in the literature from different perspectives and some literature reviews were published in this research field.

Reference [8] provided a systematic literature review focused on human errors in industrial maintenance, including studies until 2016. The review focused on exploring types and typical human errors in maintenance, error contributing factors, maintenance 
policies, methodologies for human error analysis, maintenance error consequences, and industrial sectors.

A classification framework was instead proposed by Reference [9] to organize publications from the period 2004-2015 into three main categories: workplace design/macroergonomics, human error/reliability calculation methods and human resource management.

Finally, a literature review focused on physical and physiological aspects of human factors in aircraft maintenance engineering was performed in Reference [10].

All these recent reviews showed a strong and growing interest in the research field of human issues in industrial maintenance. Indeed, humans are fundamental actors in manufacturing systems and maintenance activities are becoming more and more crucial, with respect to the past, for sustainable industrial operations. Due to such reasons, the role of maintenance operators is essential for guaranteeing safe, high-quality, and environmentally friendly operations.

The aforementioned studies were then focused on specific aspects, such as a particular industrial sector, or conventional aspects of human issues and factors in maintenance. However, the current industrial paradigm focusses on cyber-physical systems and the integration of different technologies in conventional manufacturing operations to support human performance. This, inevitably, is leading to reconsider the role of maintenance operators, creating new challenges for enterprises and several research opportunities. Besides, to the best of our knowledge, no study investigated the wide field of 'human issues in maintenance activities', providing a comprehensive and objective overview of the main topics in the subject, as well as the research challenges related to the role of maintenance operators in the factory of the future.

Therefore, this study first investigates the current state of the art role of maintenance operators in manufacturing systems, providing an overview of the main studies. A Systematic Literature Review (SLR) was conducted to identify and select the papers on the role of maintenance operators in production systems. Then, a topic modelling algorithm, based on the Latent Dirichlet Allocation (LDA) statistical approach, was used for detecting, in an objective way, the main topics of the selected papers, in order to provide the research trends on the subject. The identified topics provided interesting research insights into the human role in industrial maintenance and research trends and further research opportunities were defined.

The remainder of the article is organized as follows. Section 2 provides the research method used for the analysis, whereas Section 3 presents the results of the literature selection and topic modelling. Section 4 provides a deep analysis of the identified research trends. Finally, Section 5 presents the main conclusions, the research gaps, and proposes future research directions.

\section{Methods}

The research method consists of two steps: a systematic literature review and a topic modelling approach (Figure 1). These two steps are, respectively, presented in the following sections. 


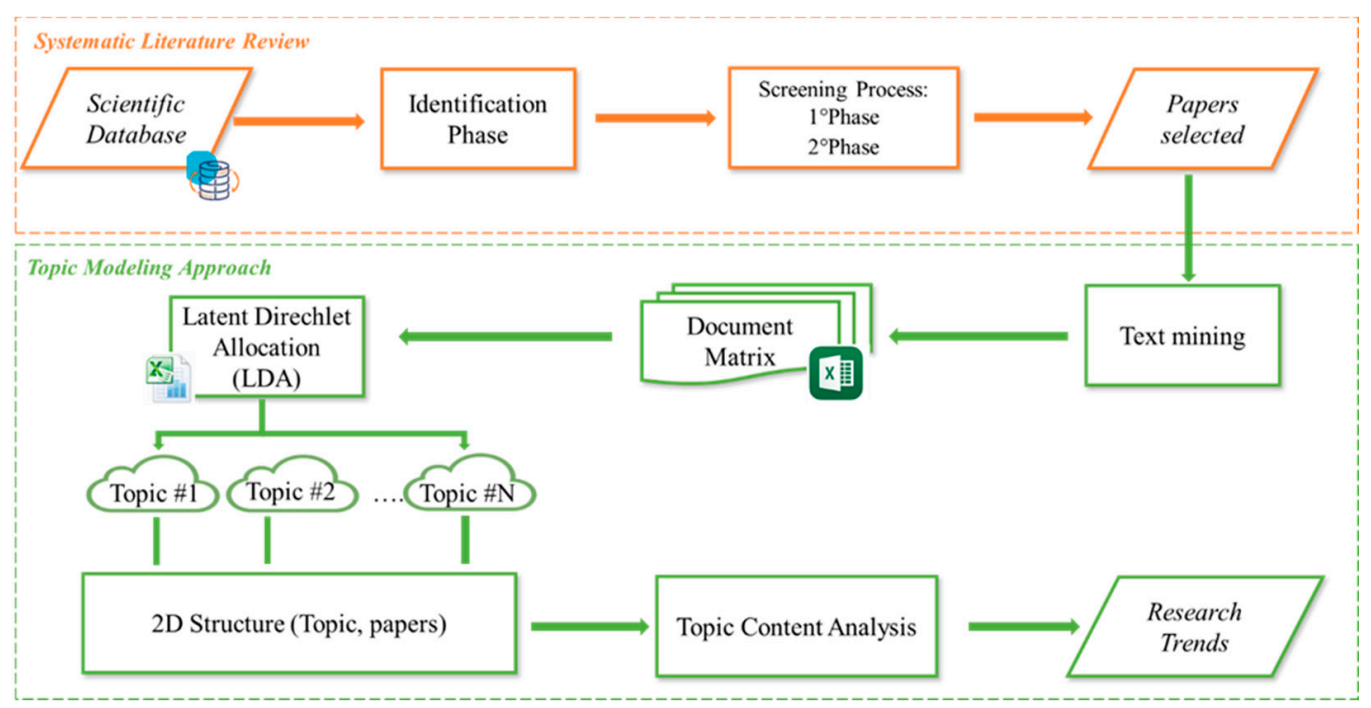

Figure 1. Research method.

\subsection{Systematic Literature Review}

The procedure presented in References [11,12] was applied to systematically analyze the scientific literature. Peer-reviewed papers on the role of maintenance operators in production systems were identified and examined. The search was conducted using the scientific database Scopus, the largest scientific multidisciplinary database of peer-reviewed literature, covering the major journal publisher (e.g., Elsevier, Taylor and Francis, Wiley, and Emerald) and conferences in the engineering and social science field.

The structured search was conducted using a set of keywords and a search string. The suitable keywords were chosen to answer the research question of the paper, specifically the role of the maintenance operator in the production systems and divided into three groups (A, B, and C), respectively, related to human, maintenance, and production systems (Table 1). The final keywords list used to search consists of all possible combinations of keywords from Groups A, B, and C using the Boolean "AND" operator to link each group (e.g., Operator AND Maintenance AND Manufacturing), with the "OR" operator used within each group. The keyword marked with an asterisk (industry*) was searched through the truncation function, which allows searching from a significant root for all the variants for that term (for example, industry, industrial, etc.).

Table 1. Groups of keywords.

\begin{tabular}{ccc}
\hline A & B & C \\
\hline OPERATOR & MAINTENANCE & INDUSTR $^{*}$ \\
WORKER & & MANUFACTURING \\
HUMAN & & PRODUCTION \\
MAINTAINER & & \\
\hline
\end{tabular}

The search was run in October 2019. Articles, including the searched keywords in their title or abstract and published in the last 15 years, between 2004 and 2019, were screened. Moreover, only articles in English and published in peer-reviewed journals, conferences or books were considered.

In the identification phase, all papers were uploaded into a database manager and the duplicates were cancelled. The screening process consisted of two steps. The first step included the reading of all title, abstract, keywords of the identified papers with the aim of excluding those without the full-text available or that were clearly out of topic, i.e., those articles that showed no relationships with the aim of this paper and therefore they did not deal with the topic of maintenance operators in industrial manufacturing systems. In the 
second screening step, instead, the full text of the papers was read, and they were included or excluded according to the exclusion criteria (EX) described below:

- EX-1: Articles did not address any human aspect in maintenance;

- EX-2: Articles in which maintenance is a secondary aspect compared to the main purpose of the article;

- EX-3: Articles in which the role of maintenance operator is a secondary aspect compared to the main goal of the article;

- EX-4: Articles only focused on the development of new technologies supporting the maintenance operator.

The selected articles were analyzed with respect to the following features: publishing type, year of publication, paper contribution and adopted research method. Then, the selected papers represented the input for the topic modelling approach.

\subsection{Topic Modelling Approach}

The Topic Modelling Approach is used to identify clusters and extract features from high-dimensional text datasets, and to discover the main themes that characterize a large and otherwise unstructured collection of documents $[13,14]$. The goal of topic modelling is to automatically discover the topics from a collection of documents.

A Latent Dirichlet Allocation (LDA) is an effective approach for topic modelling, which discovers underlying topics in a collection of documents and infers word probabilities in topics [15].

The intuition behind LDA is that documents exhibit multiple topics. LDA model is based on a probabilistic model of a corpus. Each document can be thought of as a composition, or a distribution, of latent topics, where each topic has an underlying distribution of the words in the dictionary. Each document has an underlying topic distribution, and these topic distributions are unique to each document. Each word in the document is then assumed to be drawn from one of the $\mathrm{K}$ topic distributions. The LDA algorithm assumes this process when determining the D document-topic distributions and the topic-word distributions [13]. The main outputs of the LDA model are the document-topic distribution and the topic-word distribution.

Formally, considering the same notations suggested in Reference [13], the generative process for LDA corresponds to the following joint distribution (1) of the hidden and observed variables:

$p\left(\beta_{1: K}, \theta_{1: D}, z_{1: D}, w_{1: D}\right)$

$$
=\prod_{k=1}^{K} p\left(\beta_{k}\right) \prod_{d=1}^{D} p\left(\theta_{d}\right)\left(\prod_{n=1}^{N} p\left(z_{d, n} \mid \theta_{d}\right) p\left(w_{d, n} \mid \beta_{1: K,}, z_{d, n}\right)\right) .
$$

where:

- $\quad \beta_{1: K}$ are the topics, where each $\beta_{k}$ is a distribution over the vocabulary;

- $\theta_{d}$ are the topic proportions for the $d$ th document where $\theta_{d, k}$ is the topic proportion for topic $\mathrm{k}$ in document $\mathrm{d}$;

- $\quad z_{d}$ are the topic assignments for the $d$ th document, where $z_{d, n}$ is the topic assignment for the $n$th word in document $d$;

- $\quad w_{d}$ are the observed words for document $d$, where $w_{d, n}$ is the $n$th word in document $d$, which is an element from the fixed vocabulary.

One of the distinctive features of LDA is that the set of emerged topics is certainly shared by all the documents of a collection, but each document presents those topics with different proportions.

This feature first allows us to know the topics mixture showed in each article and then to allocate each paper in a collection of scientific articles exhibiting the same topic in the highest proportion.

The principal advantages of generative models such as LDA include their modularity and their extensibility. For the aim of this study, LDA was applied using the Text Analytics Toolbox of Matlab ${ }^{\circledR}$ (R2017b). 
The phases for the Topic Modelling approach were:

- The text mining phase that involved the extraction and collection of titles, keywords, and abstracts of selected papers in the previous step.

- The result of text mining was a document matrix, whose dimensions are the selected papers and the extracted text. Document matrix was uploaded in Matlab ${ }^{\circledR}$ for subsequent analysis steps: preparation of text; creation of a "Bag of Words"; application of LDA through the fit $L D A$ function.

- The application of LDA allowed us to discover and identify the topics in the selected papers and depict them by word clouds.

- Topic Prediction Scores for each document were quantified achieving the percentage of topic distributions in each paper and a 2D structure can be achieved (Papers and Topic Prediction Scores)

- Topic distributions were then aggregated to perform Topic content analysis and define the research trends on the role of the operator in industrial maintenance.

\section{Results}

\subsection{SLR Results}

Figure 2 reports the results of the SLR process. The total number of papers achieved from the search was 5072 and reduced to 4992 after the removal of the duplicates. After the first screening step, 238 papers were recognized as pertinent. A definitive assessment, according to the 1st, $2 \mathrm{nd}, 3 \mathrm{rd}$, and 4th exclusion criteria, was performed, and 79 papers were selected in the second screening phase.

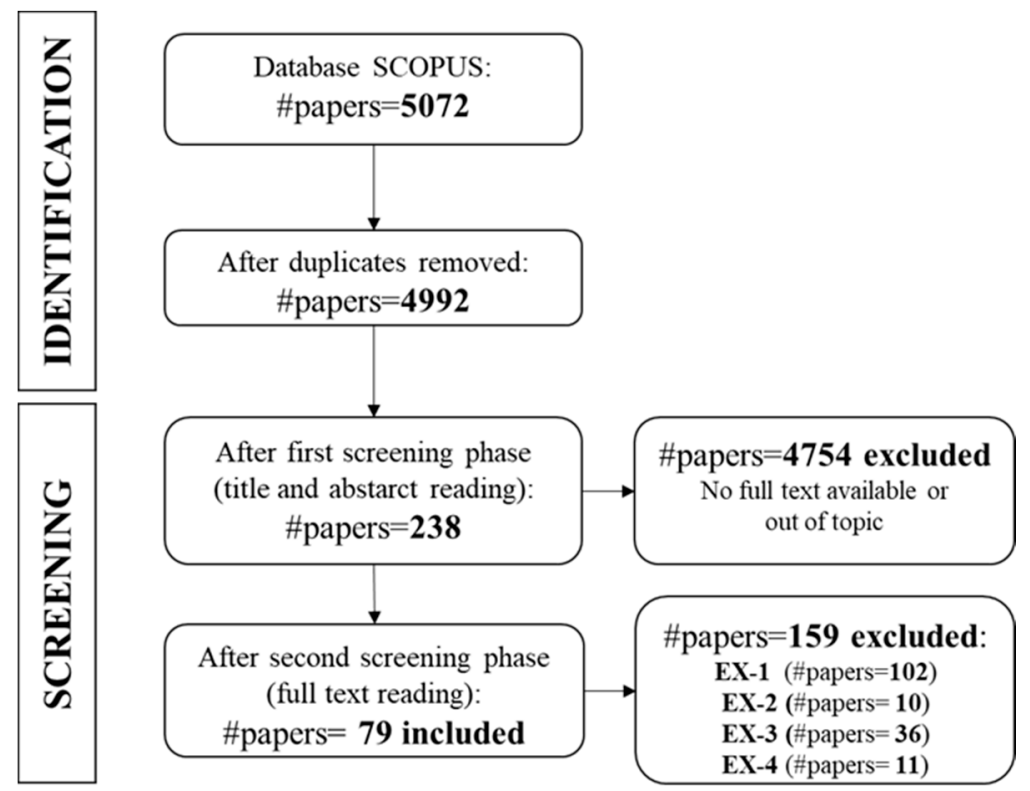

Figure 2. Systematic literature review process.

$51 \%$ of the selected papers are published in journals and $49 \%$ in conference proceedings. Several types of a journal belonging to categories "Reliability Engineering, Process Safety, human factors and Ergonomics, Quality and Mathematical Modelling" (about 40\%) were found. The distribution of the selected papers showed a positive trend over the years (Figure 3), highlighting a growing research interest. 


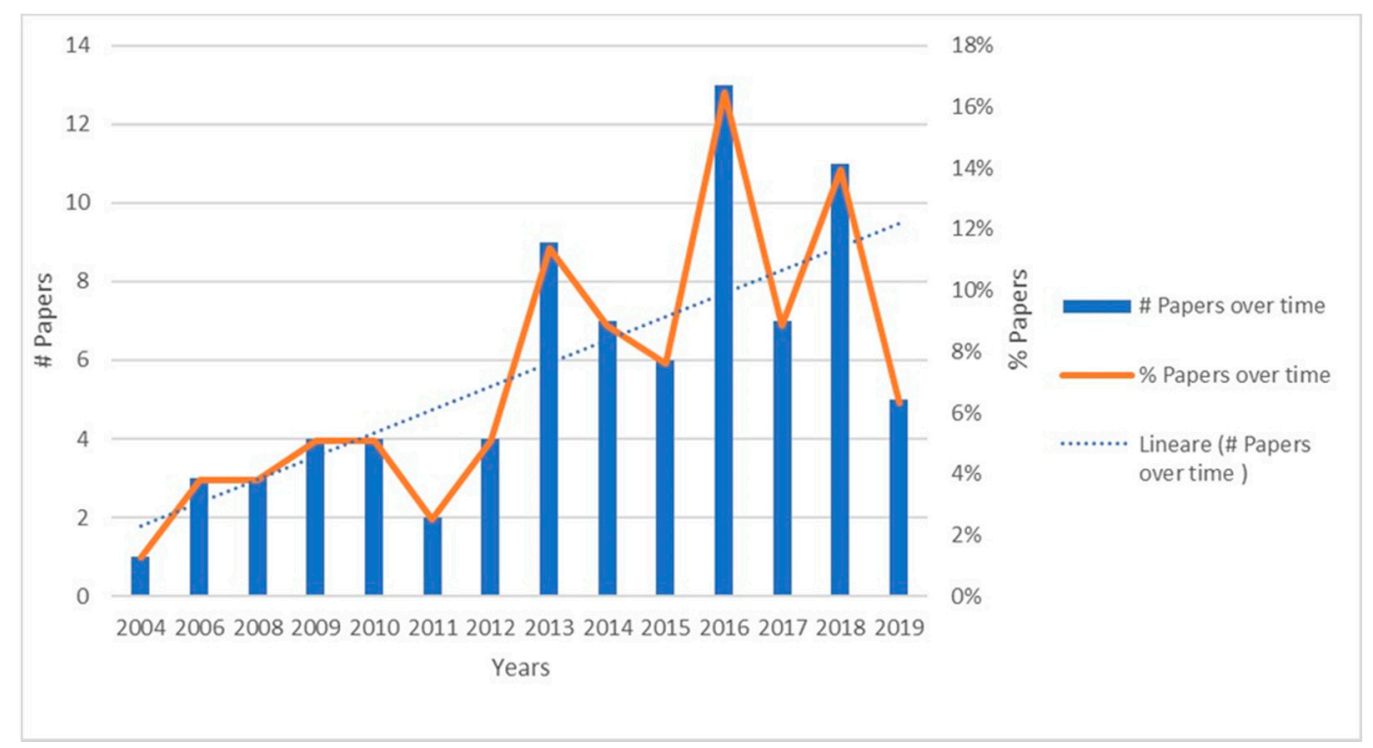

Figure 3. Publication trend by year.

In general, the temporal trend of papers selected over the years revealed an increasing interest over the last six years, from 2013 to 2019 (73.41\% of selected papers).

With respect to the type of contribution, 30 of the selected papers (38\%) developed methods, methodologies, or models; 17 papers $(21.5 \%)$ applied one or more existing methodologies or made a comparison between methods; 18 papers $(22.8 \%)$ proposed a tool; 10 papers developed a qualitative or a quantitative framework (12.7\%) and 4 papers proposed a state-of-the-art (5.1\%). On another hand, the methods adopted to conduct the research were: $62 \%$ Case study; $21.5 \%$ Experimental Research or simulation; $10.1 \%$ Literature Review or Theoretical research; 6.3\% surveys or other types of research methods (Table 2).

Table 2. Types of contribution and research method.

\begin{tabular}{cc}
\hline Contribution & \#Paper \\
\hline C1. Framework & 10 \\
C2. Methodology/model/method & 30 \\
C3. Other type of contribution & 17 \\
C4. State of art & 4 \\
C5. Tool & 18 \\
Total & $\mathbf{7 9}$ \\
\hline Research Method & \#Paper \\
R1. Case Study & 49 \\
R2. Experimental Research & 17 \\
R3. Literature Review/Theoretical research & 8 \\
R4. Other type of research method & 5 \\
Total & $\mathbf{7 9}$ \\
\hline
\end{tabular}

\subsection{Topic Modelling Approach Results}

The number of topics is a required parameter for LDA. To decide on a suitable number of topics, the goodness-of-fit of LDA model application was evaluated through the value of perplexity and the time elapsed function varying numbers of topics. This allowed us to set the number of topics, which best represented the dataset, and was equal to nine.

The implementation of the LDA approach provided two types of distributions, i.e., the topic distribution of each paper and word distribution of each topic. The identified topics are illustrated by word clouds, as reported in Figure 4. The dimension of each word in Figure 4 depends on its occurrence frequency. 

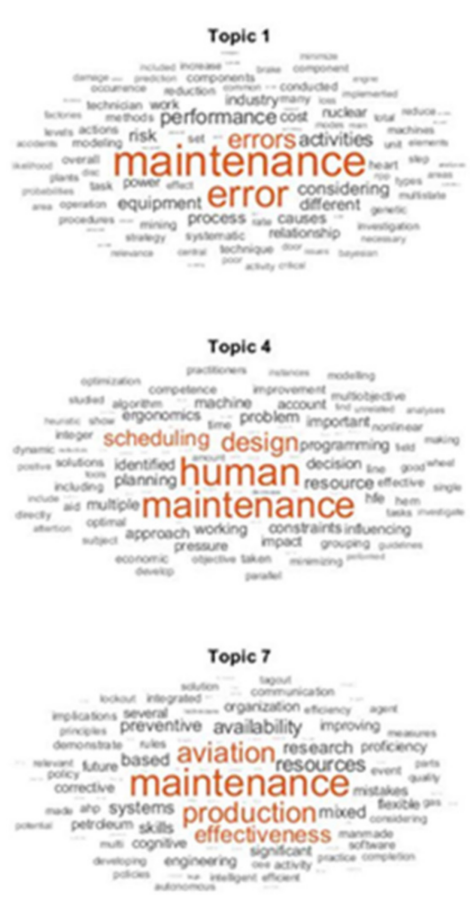
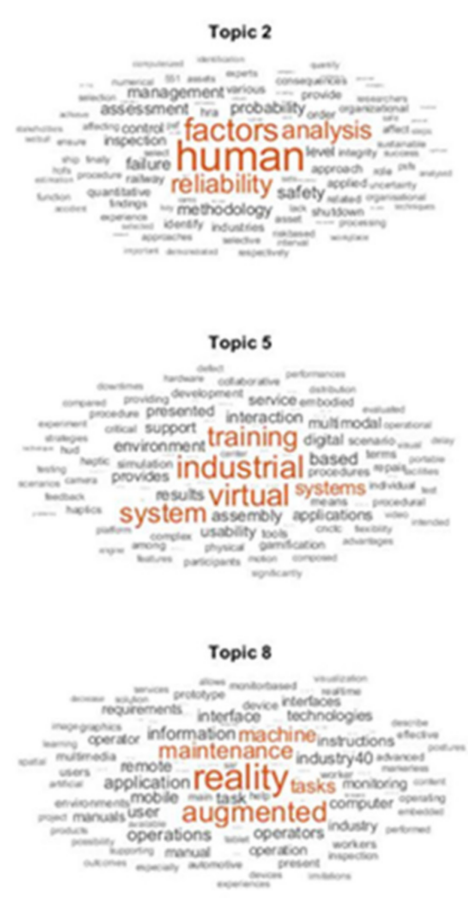

Figure 4. Word clouds.
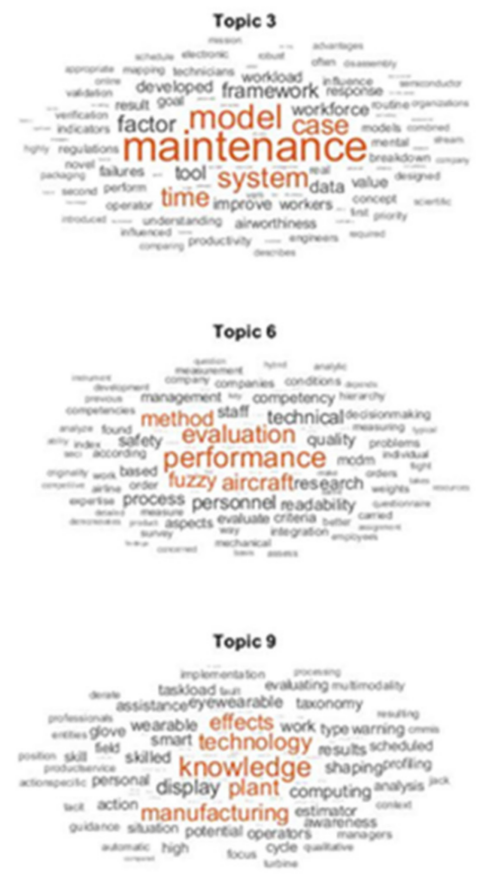

Each document presented the topics in different proportions. Figure 5 reported the distribution of the most relevant papers for each topic based on the Topic Prediction Scores.
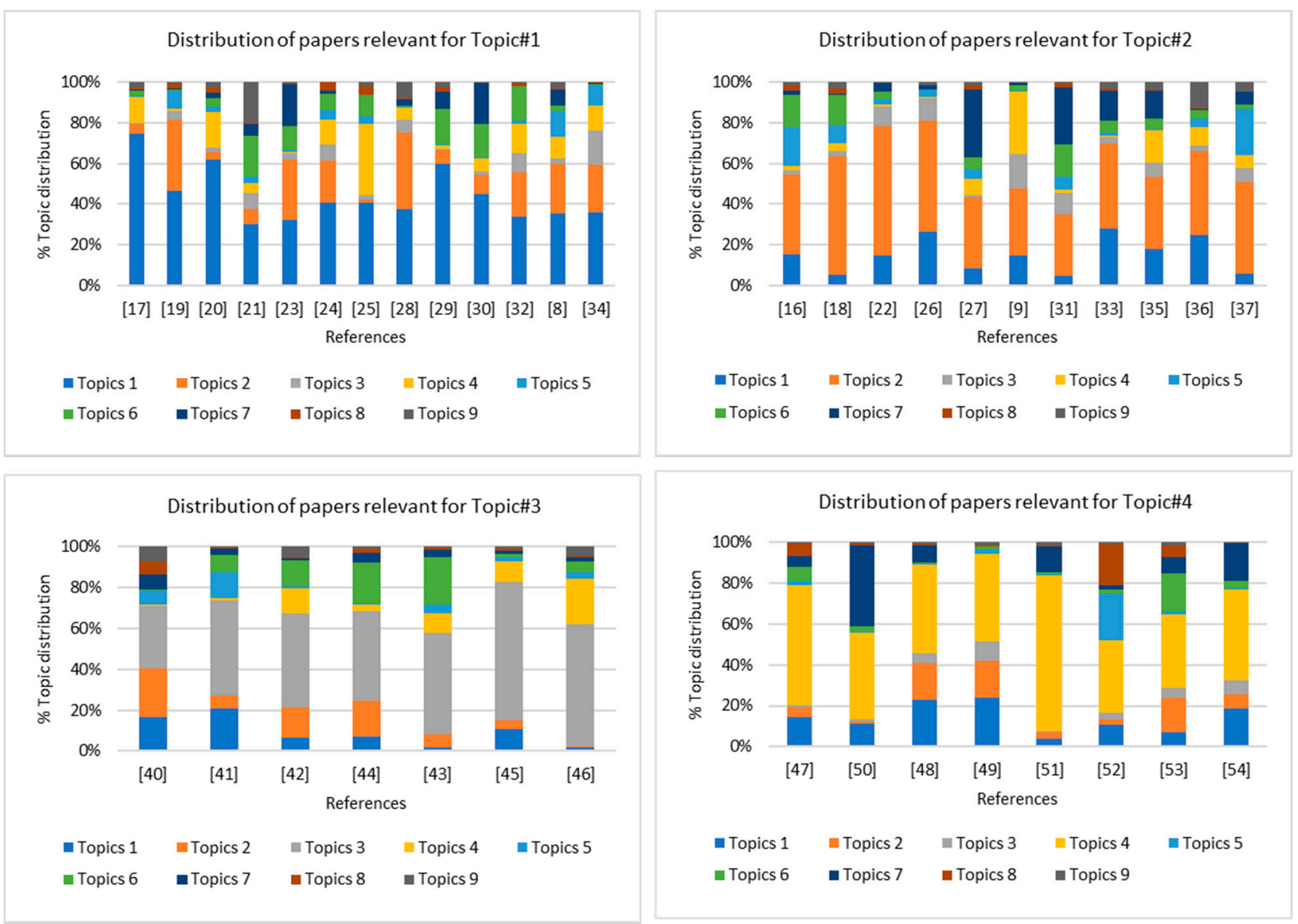

Figure 5. Cont. 

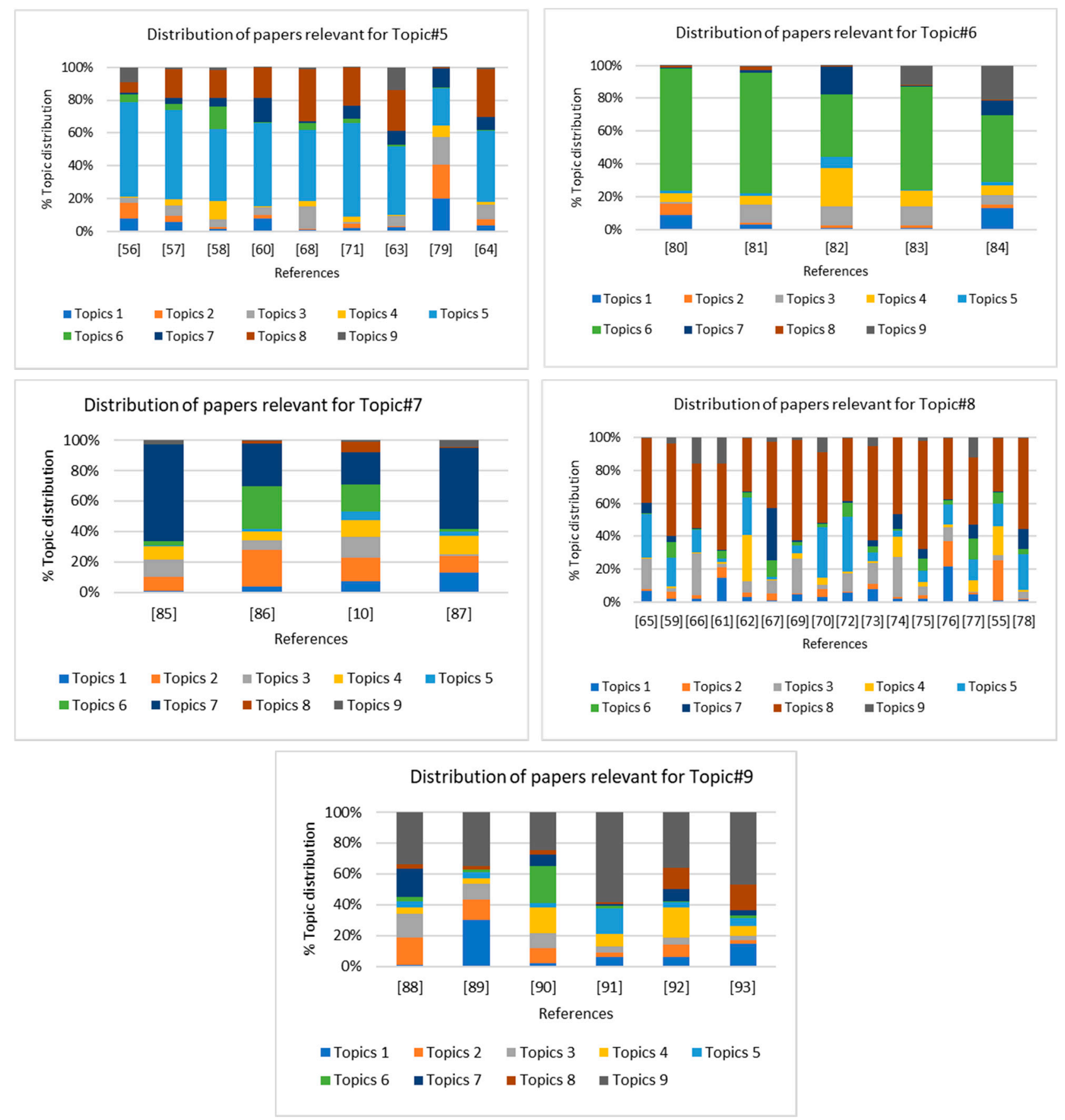

Figure 5. Topics distribution over papers.

The main terms highlighted in the word clouds composing each topic and the reading of the papers belonging to each topic allowed for the definition of the main research areas:

- Topic 1: grouped all the papers addressing the topic of human error in industrial maintenance.

- Topic 2: focuses on the papers addressing the Human Reliability Analysis (HRA).

- Topic 3: includes some general words that are frequently used in academic writing, such as: "model", "case", "tool", "system", etc. It is mostly related to several aspects of the "factors" influencing the effectiveness of the maintenance system (response time, workload, workforce). This topic aggregates papers that provided models and tools developed for measuring and improving human maintenance performance. 
- $\quad$ Topic 4: grouped all the papers focused on workplace design and human resources management (approaches for scheduling and planning) in maintenance activities.

- Topic 5: includes all the articles highlighting the importance of virtual training (VR) technology in the maintenance system.

- Topic 6: encompasses the articles addressing the issues related to skills and competences affecting maintenance personnel performance.

- Topic 7: focuses on the articles developed in the field of the aviation sector, one of the most explored in the field of human resources in maintenance.

- $\quad$ Topic 8: includes all the papers dealing with Augmented Reality (AR) technology supporting the maintenance operators.

- Topic 9: Heterogeneous topic including both papers addressing technologies' effects on operators' performance and approaches for improving operators' knowledge.

Topic 1 and Topic 2 include papers dealing with research themes in close correlation with each other; the same occurs for topic 5 and topic 8; therefore, in Section 4, they are discussed together as a unique research area.

In the next section, a deep topic description is performed through the discussion of the content articles, aggregated based on the highest score prediction for each topic.

\section{Paper Content Analysis}

\subsection{Topic 1 and Topic 2: Human Error and Human Reliability in Industrial Maintenance}

Topic 1 covered papers dealing with human error in industrial maintenance, while Topic 2 included papers dealing with the analysis of Human Factors (HF) and Human Reliability (HR). HR can be defined as the probability of humans performing specific tasks with satisfactory performance. Several methods and approaches were proposed in the literature for measuring human error and predicting human reliability during working activities. HRA aims to quantify the likelihood of human error for a given task, supports operations managers and provides guidance on how to improve reliability for that task.

Figure 6 presents the distribution trend over the years of the papers belonging to Topic 1 and $2[8,9,16-37]$ with respect to the total selected papers. These topics have been extensively covered over the years, particularly in 2013, 2014, 2015, and 2016.

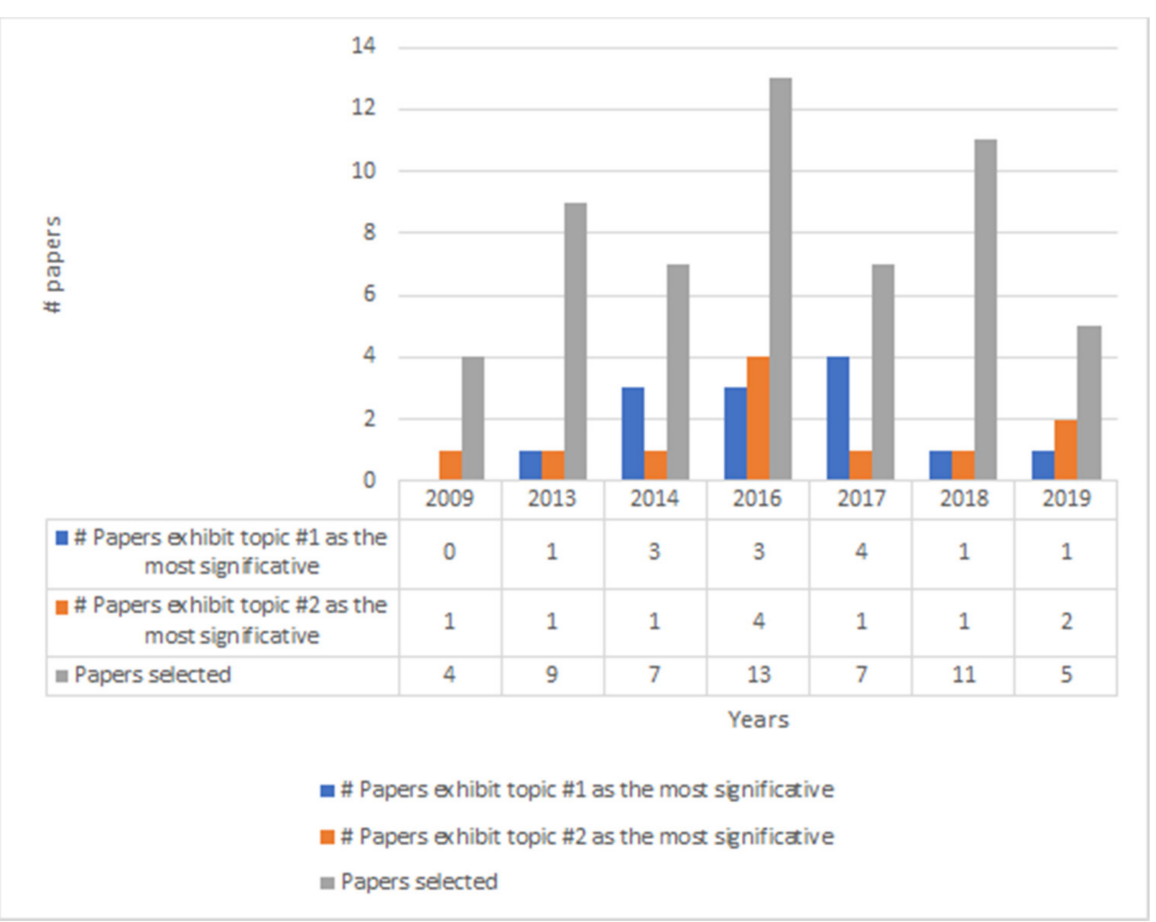

Figure 6. Distribution of the papers belonging to Topic 1 and Topic 2 over the years with respect to the total number of papers. 
Topic 1 includes several types of contributions (literature reviews, HRA models, frameworks, and case studies).

A systematic literature review on human error in industrial maintenance was conducted in Reference [8], which provides state of the art human error in maintenance, underlining several topics: methodologies for human error analysis and integration in maintenance management; error contributing factors; and maintenance error consequences. Several features of human error in maintenance, essential for improving the factories of the future, are discussed by Reference [20]. The authors provide insights into the occurrence of maintenance errors in the equipment life cycle, the causes for the maintenance error's occurrence, as well as types and typical maintenance errors, common maintainability design errors, useful design guidelines to reduce equipment maintenance errors, and maintenance error analysis methods.

Several methods for HR analysis were found in the current literature. Some were based on the risk probability assessment, such as Reference [22], which proposed a risk model for the definition of the function of reliability (or failure) of "human component" in a railway system and Reference [26], which presented a risk-based methodology to estimate shutdown inspection and the maintenance interval by integrating human errors with degradation modelling of a processing unit.

Some of the papers $[17,19,28,34]$ adopted the HRA methods, analysed maintenance error, and measured the occurrence of human error during maintenance tasks. For example, Reference [17] presents a conceptual modelling of human error, defined the system failure, listed and analysed the related human operation, estimated the error probabilities and the effects of human errors on the system. Two types of errors are considered: Error of Omission (EOO) and Error of Commission (EOC); the Swiss cheese model is used to conceptually model the problem; for the estimation of human error probabilities, the Technique for human error-rate prediction (THERP) is adopted and two cases are taken into account: in one case, the maintenance task is performed with supervision, whereas in another one without supervision. In the study proposed by Reference [19], pre and post maintenance activities of a condenser pump was investigated in order to understand the role of human error, using the Human Error Assessment and Reduction Technique (HEART). The identification of activities with high HEPs allowed us to suggest mitigation measures to reduce errors and consequently move towards lower probabilities of poor performance. The aim of the paper [28] was to validate the consistency of the three HRA methods (HEART, SPAR-H, and Bayesian Network (BN)), through a case study of a cable manufacturing company. Further, this paper demonstrated that, through an improvement in a specific factor, such as the training of personnel, a reasonable reduction of human error probability can be reached. The HRA methods take into consideration the name Performance Shaping Factors (PSFs) and the factors influencing human performance, which are determined by the individual characteristics of the human being, the environment, the organization or the activity that enhances or decreases human performance and increases or decreases the likelihood of human error $([38,39])$. Identifying the main key factors contributing errors and causes of maintenance errors is an essential aspect of HRA, and indeed, several papers were focused on References [23-25,29,32,36]. For example, the authors of the paper [29] deals with the human errors in the mining machines for the maintenance problems using fishbone cause and effect analysis, while the authors of Reference [24] presents a case study of human error probabilities in a railway maintenance system. Many factors significantly influencing human error was examined like time pressure, ability to detect and perceive problems, the existence of overriding information, the need to make absolute decisions, and a mismatch between the operator and the designer's model. The most common reasons leading humans to make mistakes of coal-mining machines were described by the authors of Reference [32], using a multi-criteria decision analysis method, able to rank and determine the key causes of maintenance errors, while the key factors of aviation maintenance errors were identified in Reference [23]. The study in Reference [36] presented a taxonomy of PSFs for the specific maintenance field. 
A considerable role is held by human and organisational factors to guarantee reliable, maintainable, and safe operation of industrial systems. Some of the papers analysed and classified the human factors, identifying the several impacts on HR [9,18,35-37].

For example, in Reference [37], critical HOFs (Human and Organisational Factors) and their effects on the reliability and maintainability of a Computerized Numerical Control Turning Center were identified. Experience, training, and behaviour were classified as the most critical human PIFs, while safety culture, problem-solving resources, corrective action programs, and training programs are the most critical organisational factors. In the study in Reference [35], a structural relationship model was developed. The model combines human and organizational factors to measure their consequences on human errors in aviation maintenance. The results highlighted that HF had a limited effect on human errors, while organizational factors had a direct and positive impact. A literature review was performed in Reference [9] to identify the human factors affecting maintenance effectiveness: wages, qualifications, motivations, like attitude, experience and human errors of maintenance personnel.

Finally, the paper in Reference [30] studied the relationship between human errors and Overall Equipment Effectiveness (OEE), showing the negative impact of human error in maintenance activities on equipment performance and safety.

\subsection{Topic 3: Measuring and Improving Maintenance Operator Performance}

The papers with high prediction scores for Topic 3 identified, analysed and measured aspects influencing the effectiveness of the maintenance system ([40-46]), through new models, tools and frameworks aimed to improve human resources in the maintenance system.

The paper in Reference [41] presented a study in which the mental workload of maintenance engineers between analogue and digital on-line maintenance systems was compared to assess and predict Reference on-line maintenance workload for digital systems. The experiment survey with 16 maintenance engineers was conducted. The results allowed us to create a model based on the neural network technique to predict the mental workload of maintenance engineers in maintaining digital systems. The model proposed improves the human resources organization as well as maintenance performance through a properly scheduling mental workload.

The paper in Reference [45] discussed the importance of response time in a maintenance system, analysing and identifying, in detail, the factors that affect response time. In particular, motion and waiting time were identified as the main causes of high response time. The paper in Reference [42] proposed a model combining the qualitative and quantitative measurements of the performed work, while Reference [43] introduced a model, called Workforce Competency Model (WFCM), for measuring individual performance. In this paper, a model has been introduced as a tool to quantify and monitor the maintenance personnel's level of competency. Since human factors and errors in aircraft maintenance may contribute to an aircraft accident/incident, a new human factor classification scheme, the A-SHELL Model (Airworthiness-Software-Hardware-Environment-Liveware), has been developed in Reference [44]. Based on airworthiness regulations, the generic human factor model is aimed at identifying less-than-satisfactory interactions between various components of the system and the aircraft maintenance staff. A non-linear integer programming model to solve a maintenance workforce sizing problems with a productivity improvement goal was proposed in Reference [46].

\subsection{Topic 4: Workplace Design and Human Resource Management}

The main subjects of Topic 4 are represented by the workplace design and the scheduling of the activities of production and maintenance under the constraints of human resources' competence and availability ([47-54]).

The manager responsible for scheduling activities must assemble and coordinate the information, people, materials, and equipment, along with all the other necessary resources 
to ensure proper tasks. Constraints related to human resources must be considered, with the aim of proposing more realistic schedules.

The maintenance activities require different competence and skill levels of maintenance in human resources based on the tasks: optimized management of human resources allows for an improvement of maintenance performance. These problems are modelled and resolved, in most cases, as optimization problems.

The single machine scheduling problem and flexible maintenance planning was studied in Reference [51], where each maintenance activity is assigned to a human resource with specific competence and some availability intervals. Reference [47] dealt with the problem of assigning tasks to maintenance operators under skill constraint, minimizing the makespan; while Reference [54] developed a mathematical model and three metaheuristic algorithms were applied to find the best solution for an open shop scheduling problem with three objective functions, i.e., human error, availability, and makespan. The authors of Reference [48] presented maintenance scheduling problem focusing on human factors and maintenance grouping, considering reliability, cost, and human error as objective functions. The HEART method was used to quantify human errors for two categories of maintenance activities, i.e., adjustment and replacement activities. A novel maintenance scheduling approach is provided in Reference [49], considering grouping strategy and focusing on human factors, while Reference [50] proposed a new joint production and maintenance scheduling that considers the human resources availability and skills to propose realistic schedules.

Human factors and the competence level of an operator are important aspects that must be considered in the assignment of maintenance tasks during the maintenance planning optimization. For these reasons, some papers belonging to this topic also exhibited high prediction scores of Topics 1, 2, and 7.

\subsection{Topic 5 and Topic 8: Virtual and Augmented Reality in Maintenance}

Topic 5 and 8 present a strong correlation, since the studies belonging to these topics discussed on the specific enabling technologies supporting maintenance human resources. Several research studies were interested in the application of augmented reality (Topic 8) and virtual reality (Topic 5), as support tools for human maintenance operations. Indeed, $33 \%$ of selected papers showed applications in this field (25 papers). Augmented Reality (AR) was highly considered in industrial maintenance and assembly tasks, whereas Virtual Reality (VR) is the main technology used for maintenance training. Enabling technologies are used for several aims, such as to support operators during a maintenance task performance, train operators for maintenance work, and ensure ergonomic activities, as well as human factors observance in the design phase.

$24 \%$ of the papers belonging to these topics showed the application of VR for operator's maintenance training; whereas $68 \%$ described advantages and applications of enabling technologies supporting the operator during maintenance activities; only one paper [55] showed the evaluation of ergonomics principles through the adoption of AR. Figure 7 provides details on the technologies adopted in the abovementioned papers and related application fields.

The distribution over the years of these two topics indicates that the interest in the past years is increasing. In 2017 and 2018, 57.1\% and 45.4\%, respectively, of the selected papers raised interesting findings on these two topics (Figure 8).

Most of the research contributions of the studies belonging to these topics are tools (61.5\%). 


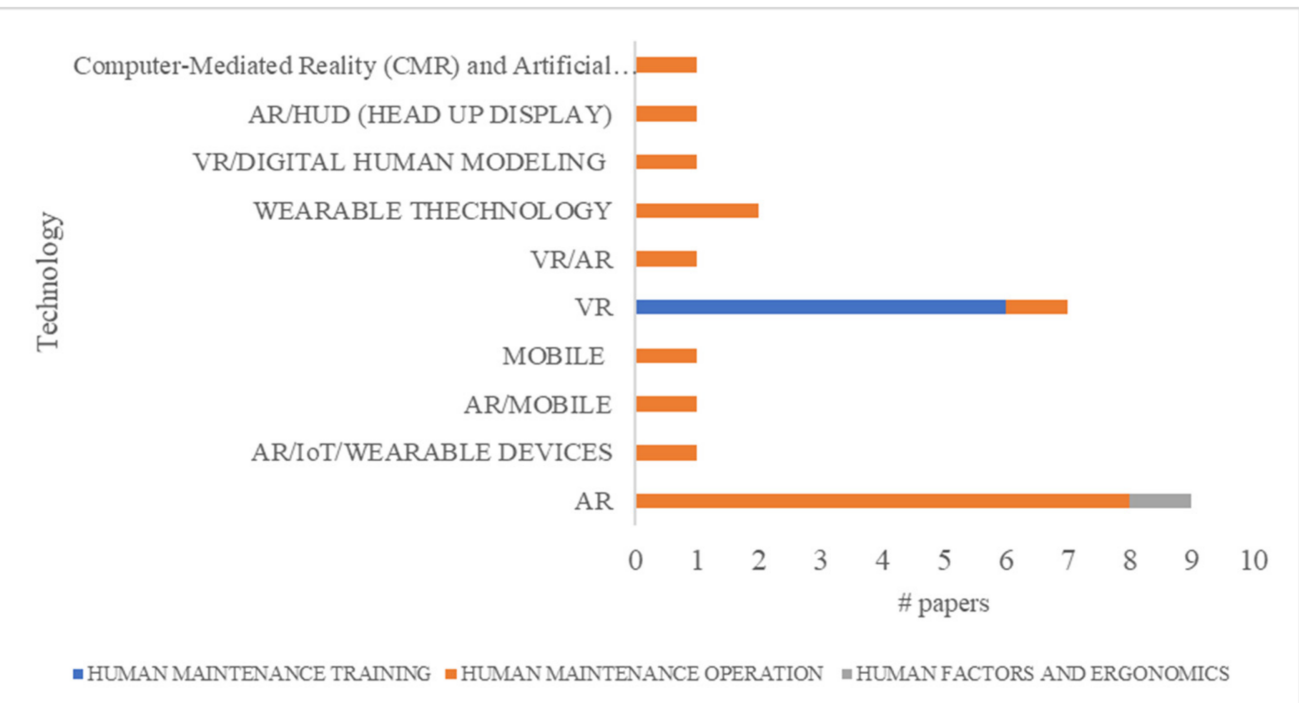

Figure 7. Numbers of papers grouped for technologies and its scope in supporting maintenance operators.

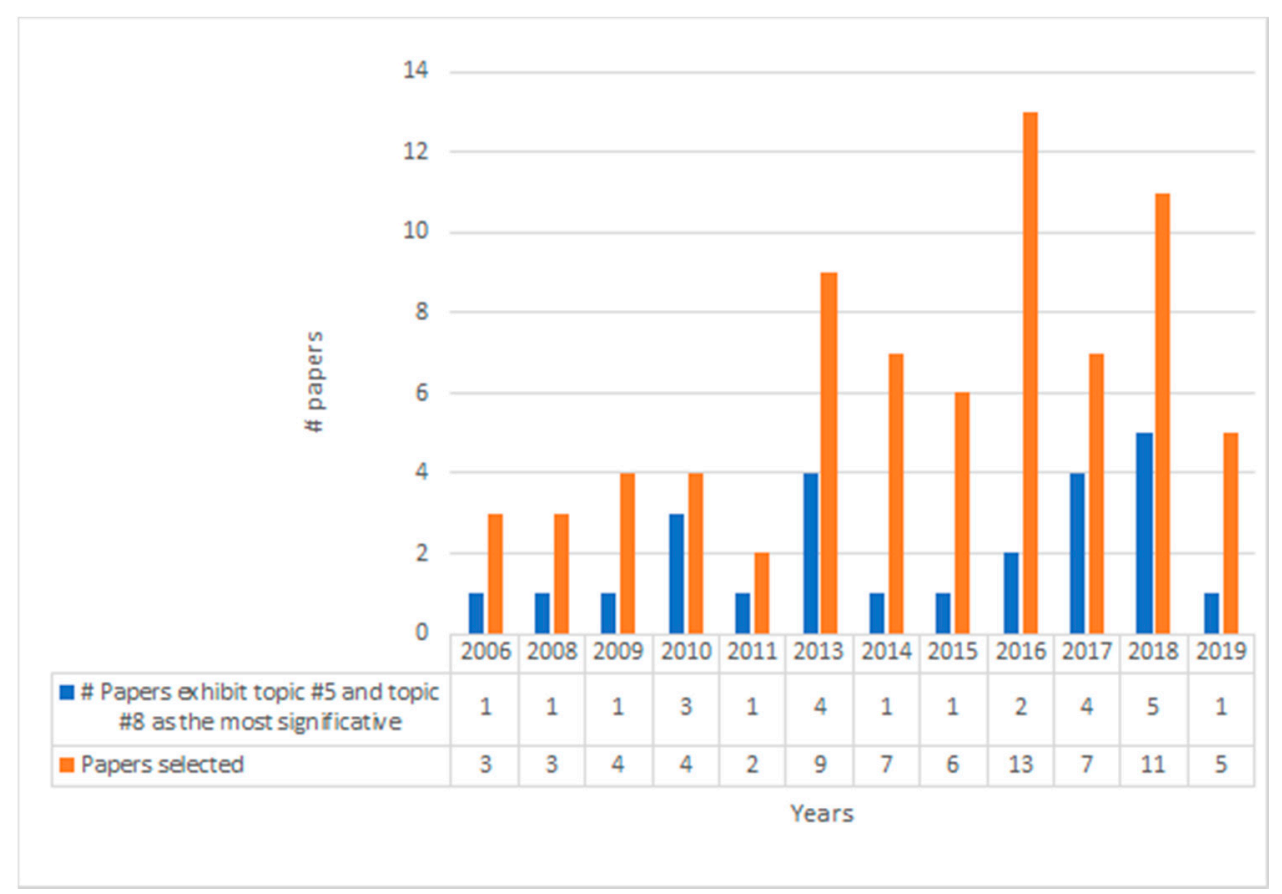

Figure 8. Distribution of the papers belonging to Topic \#5 and Topic \#8 over the years with respect to the total number of papers.

Nine papers [56-64] presented studies in the interesting field of VR (11\% of selected papers). In particular, Reference [56] focused their research on a system for virtual training on collaborative maintenance procedures rather than technical gestures, while Reference [57] addressed the simulation of the haptic feedbacks provided during the manipulation of components and equipment involved during maintenance operations in the aerospace industry: the goal was to improve the overall knowledge and efficiency of the procedures. A new multimodal training system for Industrial Maintenance and Assembly tasks based on Virtual Reality technology-the "IMA-VR" system, was proposed by Reference [60], whose aim was to provide an efficient transfer of the skills involved in procedural tasks. Instead, the development of multimedia maintenance manuals based on the synergy between VR, DHM and web-based frameworks was the focus of Reference [62]. Multimedia manuals can reduce maintenance time and cost, improving the quality of working. Finally, 
Reference [63] analysed the content of the training and then described the parts of a generic operating cycle could be supported by virtual reality.

Sixteen papers [55,65-79] were focused on AR technology (20\% of papers selected). A prototype of a monitor-based AR system is presented in Reference [65], consisting of a motorized controllable camera and a laptop with a headset. The comparison with other tools presenting instructions for maintenance operations showed that the use of this system leads to time savings and lower error rates. The tools effectiveness was measured in two ways: base on the time needed to execute maintenance tasks, and according to the error rate during maintenance intervention. Reference [66] proposed a new real-time AR based tool to help operators during disassembly operations, providing augmented instructions to efficiently perform maintenance activities.

An integrated predictive maintenance system was proposed by Reference [67], which demonstrated that, through the application of mixed visualization interfaces, which assist operators during maintenance activities, downtime is reduced, and the reliability of the maintenance operations increases.

AR technologies and mobile devices were used in Reference [69] to support maintenance services in industrial environments [69]. Specifically, 3D visual instructions are represented as in the real world through $\mathrm{AR}$ and directly visible on a mobile device. In addition, the framework introduced the possibility to monitor the operator's work from a remote location.

The study in Reference [70] presented a prototype of an interface for maintenance operators, using Gamification techniques for motivating the user, and AR and HUD to display information in an HMD device. A novel AR maintenance assistant system was described by Reference [72] enabling operators to navigate on instructions, while they are wearing gloves and handling light tools. An integrated production and maintenance schedule, supported by AR technology and real-time machine monitoring, was presented in Reference [74]. As a step towards Industry 4.0, the proposed system, through the integration of data from different systems, demonstrates the great benefits that can be obtained in the production system, as well as in maintenance activities.

The real-time communication between the planning and monitoring system, as well as the use of AR technology, allow the maintenance operator to work efficiently and consequently increase the overall performance of the system. Instead, Reference [76] discussed how Computer-mediated Reality (CMR) and Artificial Intelligence (AI) can be implemented in the energetic sector, and how they can reduce human errors, improve hazard identification, and reinforce procedure adherence. Personal Augmented Reality Reference System (PARRS) is a suite of computer-mediated reality applications that minimize human error through the digitization of manual procedures and providing real-time monitoring of possible dangers.

Papers $[58,59,64,68,71,76,77]$ belonging to this topic were all focussed on the impact assessment of technologies use on system performance. In particular, the main purpose was to evaluate the positive effects of these technologies on human performance as well as system performance, both for supporting operators during maintenance tasks and maintenance training.

Some compared performances with traditional support with respect to technologiesbased, others instead measure KPIs using technology and user experience. For example, Reference [71] conducted a study that demonstrated the advantages of using virtual-realitybased systems for training automotive assembly tasks. Sixty participants were randomly assigned to different training experiences to learn car service procedures. The results showed that virtual-trained participants, after training, can remember significantly better the correct execution of the steps with respect to video-trained trainees. The paper in Reference [58] presented a mobile assistance system for service and maintenance personnel in industrial facilities. An experiment was designed to measure three characteristics of industrial usability in compliance with EN ISO 9241-110: effectiveness, efficiency, and satisfaction. Reference [77] presented the effectiveness evaluation of providing technical in- 
structions with spatial AR prototype with respect to conventional paper-based instructions. The study conducted an experiment with 16 participants to measure user task performance (in terms of completion times and error rates) and to gather subjective evaluations. The results showed that, through spatial AR, performance significantly improved in terms of completion time (overall reduction of 20.3\%) and error rates (83.3\% fewer errors thanks to the complexity reduction given by the spatial AR adoption). An AR prototype system incorporating four efficiency requirements (user-centred, marker less camera pose, authoring procedure, simple and easy interaction), was developed in Reference [59] and showed that the AR system improved task efficiency, while Reference [64] evaluated the digital factorybased VR platform for industrial training in Reference maintenance system, and based on several criteria, made a performance comparison between traditional and VR-based training. The implementation and testing of a system whose goal is to help companies to maintain the efficiency of products during their lifecycle was described by [68]. Results showed that even users that have never used haptic devices before were capable of using the application and completing the task.

\subsection{Topic 6: Assessing Skills and Competencies of Maintenance Operator}

A lack of competence can lead to low production and a major probability that an incident occurs. Therefore, proper maintenance must assign the right people to the right position based on their skills and domains of expertise. Topic 6 covered papers proposing methods for performance evaluation in industrial maintenance ([80-84]).

Some identified and analysed criteria for enhancing the quality of maintenance activities. Reference [80] proposed an equation to evaluate the amount of unreadable sentences in aircraft maintenance technical orders since their readability can affect the quality and reliability of aircraft maintenance. Reference [81] proposed a performance evaluation model for aircraft maintenance staff, exploring the weights of different evaluation criteria (Basic Knowledge, Aircraft Maintenance Workload, Other Workload, Self-Development, Problem-Solving Skill, Problem-Solving Attitude, Responsibility, Teamwork, Work Quality, Reliability, and Attendance Rate), whereas Reference [83] proposed a competence measurement tool to assess the competency of maintenance employees, instead research modelling of plant operators' maintenance proficiency was addressed by Reference [84] to provide a classification tool to assist managers to select the best operative. In particular, three models were compared based on their robustness, efficiency, and validity, identifying the most efficient model that used the attributes of years of relevant working experience on the machine, personal disposition, and operator reliability.

\subsection{Topic 7: Human Resource Management in Maintenance of Aviation Systems}

Maintenance is crucial to ensure safety in aviation sector, and if performed incorrectly or omitted, contributes to a significant number of aviation accidents. Topic 7 , including References [10,85-87], highlighted that aviation is the most explored sector in the field of human resources in maintenance. Indeed, maintenance is a vital aspect in these industries, in which safety is an important issue, and humans represents the main resource involved in maintenance activities. Many accident reports claimed that the immediate causes of major incidents involve operators or maintenance personnel errors. Several efforts have been made and are still ongoing in the high-risk industries, like a nuclear power plant or aviation, to understand the main error contributing factors and to develop methodologies for assessment and reduction of human error in maintenance. For these reasons, papers with Topic 9's highest prediction scores showed a close link with Topic 1, 2 and 6.

Effective countermeasures to contain maintenance errors require a systemic approach, considering issues related to technicians, work environments, and organisational factors such as procedures and task scheduling. Improvements concerning training, equipment, work environment, and other conditions are some of the countermeasures oriented to reduce maintenance error probability. 


\subsection{Topic 9: Miscellaneous}

Topic 9 is heterogeneous, focused on several aspects in the investigated research field, and strictly interconnected with other topics. Other topics described so far addressed well-outlined aspects and "keywords" related to the field of human issues in industrial maintenance. The papers [88-93] characterizing Topic 9 presented approaches showing the effects of technology on operator performance and tools for improving operator knowledge.

For example, References [91-93] addressed how technologies can help humans. In particular, Reference [91] presented the prototype of a warning glove, a wearable computing device that transmits multimodal warnings to operators to assist them during maintenance tasks on micro milling machines, while Reference [92] presented an interface device to support operators during maintenance activities.

References $[56,88]$ discussed the importance of evaluating operator competences (strictly connected with Topic 6 and 7). In particular, Reference [88] developed a model for assessing plant operators' maintenance proficiency based on the attributes as years of working experience on the machine, personal disposition, and operator reliability; whereas Reference [56] provided a competence profiling tool to measure the competency of maintenance practitioners, in order to support the manager to select knowledgeable and competent operators to fulfil a certain task obtaining efficient the use of resources.

\subsection{Relationships among Topics}

All the 79 papers coming from the literature review process were discussed and considered as belonging to specific identified topics, based on the high prediction score found through the Topic modelling approach.

However, it is interesting noting that some papers presented high prediction scores also in other topics. Below some interesting examples.

Reference [21] exhibited Topic 1 and 6 as key topics, aimed at identifying aspects of the skilled technicians for proper maintenance management, as well as to establish relationships between such aspects and maintenance cost performance. Lack of competence (Topic 6) can lead to human error in maintenance activities (Topic 1). Reference [25] exhibited Topic 2 and 4 as those with high prediction scores, and indeed analysed possible aircraft incidents, their causes, performance influencing factors and information to draft a maintenance performance decision aid to be used to minimize the unreliability.

Reference [9] conducted a review on human factors in maintenance, and therefore showed topic 2 as the most significative, but almost with the same prediction score, others topics are included, and in particular topic 4 , since this research study explored different aspects of human management (e.g., design and scheduling). References [27,31] showed high prediction scores in topic 2 and topic 7 because they focused on assessing engineering measures, such as human factors (topic 2), affecting maintenance effectiveness and equipment reliability (topic 7). Reference [40] showed high predictions scores in topic 1 , topic 2 and topic 3 because they developed a model to quantify maintenance workers performance in terms of reliability through the analysis of human error (topic 1), the rating of performance shaping factors for each operator (topic 2), and probability quantification of successfully completing a task (topic 3 ).

References $[52,53]$ underlined the importance of integrating human factors and ergonomics (HFE) in the design of maintenance activities (topic 4). However, Reference [53] also presented high prediction scores in topic 4 and topic 6 because they investigated how HFE is integrated within the design process steps of the maintainability department of helicopter manufacturers in France. Instead, ref. [52] described the design process of an exoskeleton, an ergonomic device aimed at supporting maintenance operators during their work. Therefore, the exoskeleton is a technology to support workers that also represented a typical research issue of the new transformation 4.0. Indeed, Reference [52] also showed high prediction scores in topic 5 and topic 8 . Reference [82] exhibited high scores in both topic 4 and topic 6 ; in fact, they proposed an original approach to improve maintenance performance based on the optimal assignment of human resources. Finally, Reference [86] 
developed a quantitative and objective method to analyse and evaluate human factors (topic 2) in the aviation maintenance process (topic 7). The same occurred in Reference [10], which showed high scores in both topic 2 and 7 , since a review on human factors in aircraft maintenance was provided.

\section{Discussions and Research Trends}

The literature on human resources management and performance in manufacturing systems is wide and varied, but was mainly focused on the operators involved in processes like assembly, machining, or control ([94]). On the contrary, the impact of the human factors and the role of maintainers were not considered to be of interest to researchers, if not in those high-risk sectors in which man has always played an essential role. Indeed, the maintenance studies were mainly addressed to the technological and reliability aspects, and only in the last decade, the role of the people involved in this process has proven to be fundamental for the correct execution of maintenance activities. This is evident from the results of our review, which highlighted how the interest in this topic has gradually increased since 2013.

The literature reviewed showed that the traditional methodologies developed to evaluate and improve the reliability of the operators, the management and scheduling strategies of the work activities, as well as the approaches to evaluate the operators' skills and competences were also applied to the maintenance context, allowing to explore a different environment with respect to the one for which they had been developed, leading to the birth of specific methodologies and approaches for maintenance field.

At the same time, the progress of technologies and the evolution of the smart factory paradigm has led to the introduction in the industrial contexts of various types of enabling technologies to support and help the maintenance operator in carrying out his/her working activities.

The analysis of the papers' contents and the identified topics allowed us to identify three main research trends, reported, and described below:

1. TREND 1: Human reliability in maintenance activities;

2. TREND 2: Maintenance management strategies;

3. TREND 3: Supporting technologies for maintenance tasks.

TREND 1 focused on several approaches that were developed and used in the literature, having as a common goal the improvement of the maintenance worker's reliability level, and more generally, of the complex systems within the operator works. Despite technological improvements in the manufacturing systems, the human element remains essential to the quality of the work performed [42]. Over the years, several human reliability assessment (HRA) methods and approaches have been proposed to carry out a structured analysis of human reliability and human error probabilities for different industrial activities, as well as for the maintenance process. There are different techniques available to obtain a quantitative measure of human error probability (HEP). Based on the advantages and disadvantages of each technique, the selection of the most suitable traditional HRA technique, under the specific maintenance scenarios, was applied by most of the papers. All the papers are mainly focused on applying of existing methodology HRA for maintenance activity, on the classification and evaluation of PSF in a specific maintenance process, on investigating the main causes of human error in maintenance while only one paper highlights the effect of human error on machine performance. While the trend reveals a decline in the human error and reliability analysis over the years, the topic is still discussed in some studies because it can be considered as the starting point for human maintenance performance evaluation on a manufacturing system.

TREND 2 focuses on various organizational and managerial aspects impact considerably on the maintenance operator's performance, such as scheduling activities or assigning the right person to the right task. Human resource management is an important industrial challenge that maintains the level of global performance of manufacturing systems. This problem affects all industrial activities in general and maintenance activities. An 
improvement in company performance depends, in part, on an optimized management of human resources, and in maintenance, this issue is studied from several points of view. Indeed, in maintenance scheduling activity, the problem of human factors is an interesting investigation area faced by several studies. Positive effects in the improving maintenance program were obtained by including human constraints (such as availability, competences level, and error) in a maintenance-scheduling problem. Production scheduling generally requires a controlling agent of the production process, whereas maintenance activities require specified agents that are characterized by skill levels and qualifications ([51]), allowing them, or not, a good execution of the maintenance activities. Maintenance operators proficiency and competency mapping plays a key role in the human resource assignment problem. The measurement of their performances has become essential. The major aspect, discussed in some papers, is assessing the current competencies of an employee. Different models, framework, and tools for evaluating operators' qualification level, through the classification of variables affecting human performance, have been proposed. The outcomes demonstrated the importance of measuring competences to gain high levels of business performance.

TREND 3: Finally, the review results showed an increasing interest concerning the emerging supporting technologies in maintenance activities. Industry 4.0 is a current trend in the manufacturing field, based on the concept of "smart factory". Industry 4.0 provides several enabling technologies for supporting the maintenance operator in performing a task or in maintenance training. VR is a key technology for industrial training used in the digital factory. VR allows for the creation of an environment through the use of computer technology to develop the condition of an interactive 3D world in which objects have a sense of spatial presence [95]. The new training method enables the operator to interact with the prospective work object even without the presence of the training object, giving him the chance to train at any desired place. Studies showed VR technology can improve maintenance system training by reducing the time for training and by enhancing cognitive skills and motor skills for performing a task. Another relationship between the investigation field with enabling technology of industry 4.0 is represented by Augmented Reality (AR) technology. Several studies showed the application of AR supporting the human maintenance operation through a mobile or wearable device to plan and perform maintenance tasks efficiently and in easier way, increasing the productivity of the system. The experimental research of some papers demonstrated how enabling technologies can help human resources to reduce time and errors of maintenance tasks. The current research trends in this field aims to reduce maintenance costs through the enhancement of the operator's performance at work. In particular, technologies supporting operators aim to reduce the error rate during the execution of maintenance activity, the time of completion task and to improve the quality of work; another trend aims at reducing time and cost for the training by providing supports for instructions that are more accessible and easier to understand also for an unskilled operator.

Figure 9 shows the relationship of the different topics obtained from the LDA approach with the identified trends, as discussed above. Summarizing some topics univocally belong to one of the identified trends. Other topics, instead, are distributed among more than one identified trend, since addressed and investigated research subjects belonging to different areas. 

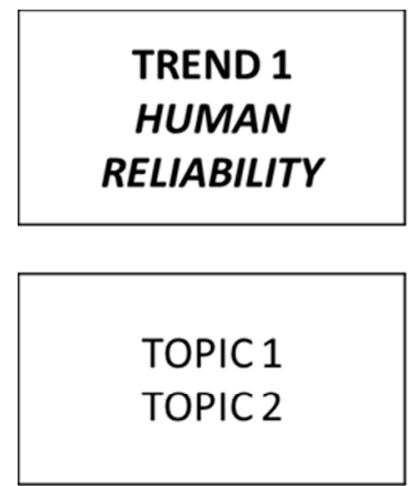
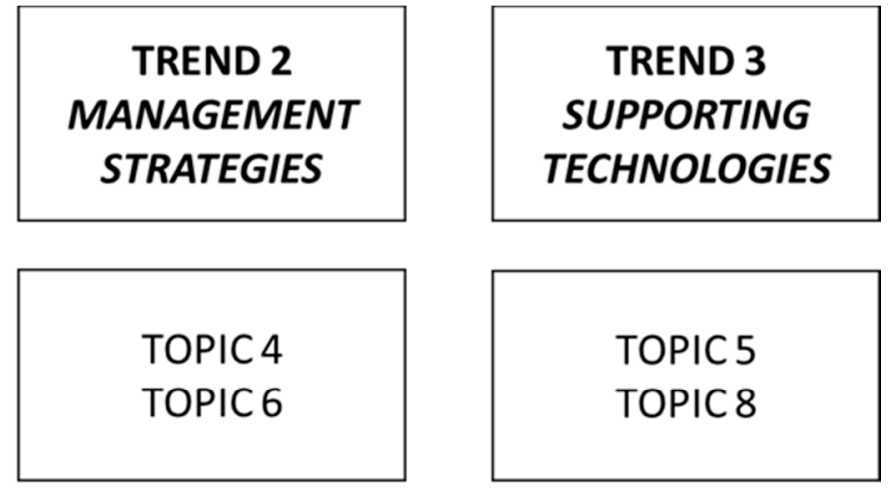

\section{TOPIC 3}

TOPIC 7

\section{TOPIC 9}

Figure 9. Topics grouped into the research trends identified.

\section{Research Agenda}

Review results underlined that the performance of maintenance operator depends on numerous individuals, environmental and organizational factors. It is essential to know and manage these aspects because they have impacts on both the single maintenance task and the overall system.

Figure 10 shows the conceptual framework achieved through the analysis of the selected papers. The framework underlines the research agenda in the investigated field and the identified research trends, shedding light on several research opportunities.

The research field analyzed in this paper is highly heterogeneous and varied, as evidenced by the topics identified through the LDA approach. Furthermore, several gaps have been found in current literature, which then represents future research opportunities (ROs).

Research Opportunity 1 (RO1): First of all, despite several HRA models and their applications, there are no approaches developed with the specific purpose of assessing the maintenance operator's reliability. Several efforts have been made and are still ongoing in the high-risk industries, like NPP or aviation, in order to understand the main error contributing factors and to develop methodologies for the assessment and reduction of human error in maintenance, as underlined by Reference [8], but the same is not true for other industrial sectors, as particularly manufacturing, where there is a need to be filled. A first step in this direction was proposed by Reference [36], where a taxonomy of PSF for the specific maintenance field was proposed. Furthermore, as underlined in the results section, trends 1 and 2 showed several links. Many of the decision and management models developed in the papers belonging to the trend 2 exploited the HRA methodologies and approaches, which characterize the first trend. However, there are few relations with the third trend. No paper exhibits both topic on enabling technologies and human reliability or factors influencing maintenance performance with the introduction of new technologies. The quantification of human reliability during a maintenance activity supported by the new technologies is an uncommon issue not discussed in the literature. In current literature, indeed, the study of maintenance operator reliability supported by new technologies as well as the identification, analysis, and classification of new PSFs that affect performance are missing.

For these reasons, new HRA methods ad-hoc for evaluating maintenance processes, and including all the impacting factors (trend $1+2+3$ ), should be proposed. The verticalization of the HRA methods on maintenance activities will allow us to evaluate for the specific maintenance tasks the performance of the operators and the main impacting factors, and therefore to identify the main causes of problems, in order to mitigate and 
reduce these errors and improve the health and safety of the operators, as well as the performance of the system.

Research Opportunity 2 (RO2): This need becomes increasingly evident when one considers the evolution taking place in manufacturing systems. The Industry 4.0 paradigm is transforming the concept of traditional production systems into the widespread model of smart manufacturing, however, is not just about technology, it is also a new cultural paradigm with an impact on the workforce at all levels and for all business functions. The Industry 4.0 paradigm is changing the roles and job requirements of employees, influencing the workers and the nature of their work, and creating new interactions, not only between humans and machines but also between the digital and physical worlds. While significant attention has been given to the technologies for the past decade, the human element is still important [96]. This led to the spread of the new term of operator 4.0 as a relatively new term $[97,98]$, which evolved from an analogy of the industrial revolution concept mentioned earlier. The generation of Smart Operators carry out the work interacting with collaborative robots, advanced systems and sensors, and enriches the realworld with AR and VR technologies [99]. However, if many of the enabling technologies introduced to make smart maintenance operators offer support and advantages, these technologies also profoundly change the execution of maintenance activities and can also have negative impacts on human performance, considering the possible obstacles related to the adaptation to new technologies, and the learning of operators. Therefore, the correct interaction between the workforce and the enabling technologies of paradigm 4.0 is a crucial aspect for the success of the smart factory. As this interaction will certainly be affected by the variability of maintenance operator behaviour and its reliability, which can strongly influence productivity and safety standards. This aspect is missing in the current literature, which, as highlighted above, has investigated the use of some 4.0 technologies in the field of maintenance, emphasizing only the positive aspects of their use. No one studies the difficulties in maintenance environment; in addition, the estimate of the error, the consequences and/or impacts on business performance is not clarified. The fields of use, the advantages and disadvantages, and the relationships with the performance of maintenance operators should be further investigated and studied to understand the real benefits of integrating these technologies.

Research Opportunity 3 (RO3): While human performance leads to critical consequences in terms of safety, quality, system reliability and economic and environmental impacts, such aspects have been not deeply investigated in existing literature and integrated in maintenance management policies.

Indeed, few studies investigated the consequences of maintenance operator performance on maintenance systems, and consequently, on manufacturing systems. The results of our study showed that only one paper underlined the relationship between human error and the overall equipment effectiveness (OEE) of an equipment distinguishing the effect of the HE on the three components of the index: quality rate, performance rate and availability rate [30].

A further research opportunity should be the development of methodologies and approaches to assess and measure human performance consequences and impacts on manufacturing systems. These impacts should be considered in terms of system availability and reliability (e.g., frequency of maintenance intervention or length of intervention time), safety, productivity, efficiency, quality, sustainability, and therefore, costs. 


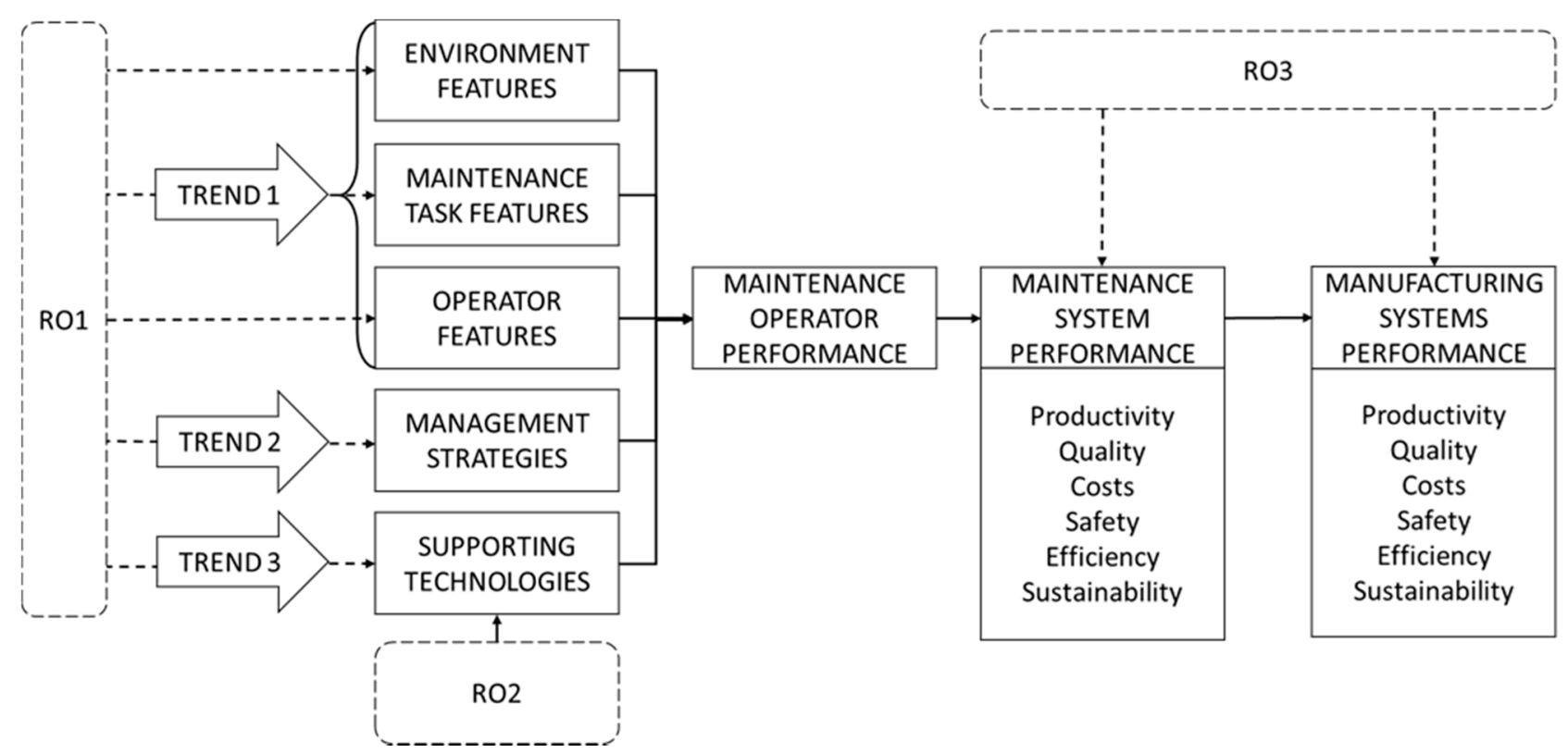

Figure 10. Research agenda.

\section{Conclusions}

The literature review conducted in this paper allowed us to investigate the current state of the art role of maintenance operators in manufacturing systems, providing an overview of the main studies. Seventy-nine papers were selected and analysed to identify the research trends investigated in recent years. The identified trends highlighted three main research fields in which researchers focused their efforts in the past years: Human reliability in maintenance activities; Maintenance management strategies; and Supporting technologies for maintenance tasks.

However, the role of the maintenance operator is not yet addressed in the literature considering in depth the numerous factors that impact on human performance (individual, organizational, technological and environmental) and integrating the "human component" within the wider manufacturing system.

This study provides interesting research insights into the human role in industrial maintenance, and the identified research gaps underline paths for further research opportunities in this field. Further steps should: address the development of new HRA methods ad-hoc for evaluating maintenance processes; investigate the emerging supporting technologies, the fields of use, the advantages and disadvantages, in relation to the performance of the maintenance operator; and focus on the development of methodologies and approaches to assess and measure human performance consequences and impacts on manufacturing systems.

Based on the lessons learnt from this analysis, organisations must become more aware of the importance of the role of the maintenance operator on the manufacturing system. Indeed, this paper highlighted that business benefits can be achieved on the identified KPIs (productivity, quality, costs, safety, efficiency, and sustainability) if the operator's maintenance management is improved.

Author Contributions: Conceptualization, Writing-review and editing: A.M.R.T., V.D.P., C.F., S.M. and R.I.; Methodology, Formal Analysis, Investigation, Data Curation and writing-original draft preparation: A.M.R.T., V.D.P. and C.F.; Visualization, Supervision, Project administration and Funding acquisition: S.M. and R.I. All authors have read and agreed to the published version of the manuscript.

Funding: This research work was funded by the Italian Ministry of Education, Universities and Research MIUR, SO4SIMS project (Smart Operators 4.0 based on Simulation for Industry and Manufacturing Systems, Project-PRIN-2017FW8BB4). 
Conflicts of Interest: The authors declare no conflict of interest.

\section{References}

1. Al-Najjar, B.; Alsyouf, I. Selecting the most efficient maintenance approach using fuzzy multiple criteria decision making. Int. J. Prod. Econ. 2003, 84, 85-100. [CrossRef]

2. Lu, B.; Zhou, X. Quality and reliability oriented maintenance for multistage manufacturing systems subject to condition monitoring. J. Manuf. Syst. 2019, 52, 76-85. [CrossRef]

3. Franciosi, C.; Lambiase, A.; Miranda, S. Sustainable Maintenance: A Periodic Preventive Maintenance Model with Sustainable Spare Parts Management. IFAC-PapersOnLine 2017, 50, 13692-13697. [CrossRef]

4. Franciosi, C.; Iung, B.; Miranda, S.; Riemma, S. Maintenance for sustainability in the industry 4.0 context: A scoping literature review. IFAC-PapersOnLine 2018, 51, 903-908. [CrossRef]

5. Ruschel, E.; Santos, E.A.P.; Loures, E.D.F.R. Industrial maintenance decision-making: A systematic literature review. J. Manuf. Syst. 2017, 45, 180-194. [CrossRef]

6. Di Pasquale, V.; Miranda, S.; Neumann, W.P.; Setayesh, A. Human reliability in manual assembly systems: A Systematic Literature Review. IFAC-PapersOnLine 2018, 51, 675-680. [CrossRef]

7. Di Pasquale, V.; Miranda, S.; Iannone, R.; Riemma, S. A Simulator for Human Error Probability Analysis (SHERPA). Reliab. Eng. Syst. Saf. 2015, 139, 17-32. [CrossRef]

8. Di Pasquale, V.; Franciosi, C.; Iannone, R.; Malfettone, I.; Miranda, S. Human error in industrial maintenance: A systematic literature review. In Proceedings of the Summer School Francesco Turco, Palermo, Italy, 13-15 September 2017.

9. Sheikhalishahi, A.; Pintelon, M.; Azadeh, L. Human Factors in Maintenance: A review List of abbreviations. J. Qual. Maint. Eng. 2016, 22, 218-237. [CrossRef]

10. Shanmugam, A.; Robert, T.P. Human factors engineering in aircraft maintenance: A review. J. Qual. Maint. Eng. 2015, 21, 478-505. [CrossRef]

11. Di Pasquale, V.; Nenni, M.E.; Riemma, S. Order allocation in purchasing management: A review of state-of-the-art studies from a supply chain perspective. Int. J. Prod. Res. 2020, 58, 4741-4766. [CrossRef]

12. Franciosi, C.; Voisin, A.; Miranda, S.; Riemma, S.; Iung, B. Measuring maintenance impacts on sustainability of manufacturing industries: From a systematic literature review to a framework proposal. J. Clean. Prod. 2020, 260, 121065. [CrossRef]

13. Blei, D.M.; Carin, L.; Dunson, D.B. Probabilistic Topic Models. IEEE Signal Process. Mag. 2010, 27, 55-65. [CrossRef] [PubMed]

14. Zhang, Y.; Wei, H.; Ran, Y.; Deng, Y.; Liu, D. Drawing openness to experience from user generated contents: An interpretable da-ta-driven topic modeling approach. Expert Syst. Appl. 2020, 144, 113073. [CrossRef]

15. Campbell, J.C.; Hindle, A.; Stroulia, E. Latent Dirichlet Allocation: Extracting Topics from Software Engineering Data. Art Sci. Anal. Softw. Data 2015, 3, 139-159.

16. Szwarcman, D.M.; Domech, J.; Tanscheit, R.; Vellasco, M.; Pacheco, M.; Ribeiro, N.P. A fuzzy system for the assessment of human reliability. In Proceedings of the International Fuzzy Systems Association World Congress and European Society for Fuzzy Logic and Technology Conference, IFSA-EUSFLAT 2009, Lisbon, Portugal, 20-24 July 2009.

17. McLeod, J.E.N.; Rivera, S.S. Human error on the risk reduction actions during the NPP maintenance. In Lecture Notes in Engineering and Computer Science; Springer: Berlin/Heidelberg, Germany, 2013.

18. Ratnayake, R.C. Sustainable performance of industrial assets: The role of PAS 55-1\&2 and human factors. Int. J. Sustain. Eng. 2013, 6, 198-211.

19. Noroozi, A.; Khan, F.; Mackinnon, S.; Amyotte, P.; Deacon, T. Determination of human error probabilities in maintenance proce-dures of a pump. Process Saf. Environ. Prot. 2014, 92, 131-141. [CrossRef]

20. Dhillon, B.S. Human error in maintenance: An investigative study for the factories of the future. In IOP Conference Series: Materials Science and Engineering; IOP Publishing Ltd.: Bristol, UK, 2014; Volume 65.

21. Au-Yong, C.P.; Ali, A.S.; Ahmad, F. Optimising maintenance cost performance with skilled technicians. Struct. Surv. 2014, 32, 238-245. [CrossRef]

22. Lombardi, M.; Guarascio, M.; Rossi, G. The management of uncertainty: Model for evaluation of human error probability in railway system. Am. J. Appl. Sci. 2013, 11, 381-390. [CrossRef]

23. Zhou, X.; Zhou, D.; Guo, Z.; Zhang, W. A cognitive reliability assessment method for aviationmaintenance error. In Proceedings of the First International Conference on Reliability Systems Engineering (ICRSE), Beijing, China, 21-23 October 2015.

24. Singh, S.; Kumar, R. Evaluation of Human Error Probability of Disc Brake Unit Assembly and Wheel Set Maintenance of Railway Bogie. Procedia Manuf. 2015, 3, 3041-3048. [CrossRef]

25. Feroz, K.M.; Yanjun, L. Maintenance Performance Decision Aid. In Proceedings of the First International Conference on Reliability Systems Engineering (ICRSE), Beijing, China, 21-23 October 2015.

26. Hameed, A.; Khan, F.; Ahmed, S. A risk-based shutdown inspection and maintenance interval estimation considering human error. Process. Saf. Environ. Prot. 2016, 100, 9-21. [CrossRef]

27. Mkilania, J.N. Factors related to human resources affecting the maintenance effectiveness in Tanzanian industries. Int. J. Mech. Eng. Technol. 2016, 7, 150-160.

28. Aalipour, M.; Ayele, Y.Z.; Barabadi, A. Human reliability assessment (HRA) in maintenance of production process: A case study. Int. J. Syst. Assur. Eng. Manag. 2016, 7, 229-238. [CrossRef] 
29. Papic, L.; Kovacevic, S.; Galar, D.; Thaduri, A. Investigation of Causes of Mining Machines Maintenance Problems. In Lecture Notes in Engineering and Computer Science; Springer: Berlin/Heidelberg, Germany, 2016.

30. Ngadiman, Y.; Hussin, B.; Hamid, N.A.A.; Ramlan, R.; Boon, L.K. Relationship between human errors in maintenance and overall equipment effectiveness in food industries. In Proceedings of the International Conference on Industrial Engineering and Operations Management, Kuala Lumpur, Malaysia, 8-10 March 2016.

31. Antonovsky, A.; Pollock, C.; Straker, L. System reliability as perceived by maintenance personnel on petroleum production facil-ities. Reliab. Eng. Syst. Saf. 2016, 152, 58-65. [CrossRef]

32. Kovacevic, S.; Papic, L.; Janackovic, G.; Savic, S. The analysis of human error as causes in the maintenance of machines: A case study in mining companies. S. Afr. J. Ind. Eng. 2016, 27, 193-202. [CrossRef]

33. Allal, A.A.; Mansouri, K.; Qbadou, M.; Youssfi, M. Task human reliability analysis for a safe operation of autonomous ship. In Proceedings of the 2nd International Conference on System Reliability and Safety (ICSRS), Milan, Italy, 20-22 December 2017.

34. Zhao, Z.; Yan, X.; Xiao, B.; Sun, X. Selective Maintenance Modeling for a Multi-State System Considering Human Reliability. In Proceedings of the 3rd International Conference on System Reliability and Safety (ICSRS), Barcelona, Spain, 24-26 November 2018.

35. Padil, H.; Said, M.N.; Azizan, A. The contributions of human factors on human error in Malaysia aviation maintenance industries. In IOP Conference Series: Materials Science and Engineering; IOP Publishing: Bristol, UK, 2018.

36. Franciosi, C.; Di Pasquale, V.; Iannone, R.; Miranda, S. A taxonomy of performance shaping factors for human reliability analysis in industrial maintenance. J. Ind. Eng. Manag. 2019, 12, 115. [CrossRef]

37. Patil, R.B. Integrated reliability and maintainability analysis of Computerized Numerical Control Turning Center considering the ef-fects of human and organizational factors. J. Qual. Maint. Eng. 2019. [CrossRef]

38. Di Pasquale, V.; Fruggiero, F.; Iannone, R.; Miranda, S. A model for break scheduling assessment in manufacturing systems. Comput. Ind. Eng. 2017, 111, 563-580. [CrossRef]

39. Di Pasquale, S.; Miranda, V.; Iannone, S.; Riemma, R. Simulative analysis of performance shaping factors impact on human reli-ability in manufacturing activities. In Proceedings of the 27th European Modeling and Simulation Symposium, Bergeggi, Italy, 21-23 September 2015; p. 93.

40. Razak, I.H.A.; Kamaruddin, S.; Azid, I.A. Development of Human Reliability Model for Evaluating Maintenance Workforce Reliability: A Case Study in Electronic Packaging Industry. In Proceedings of the IEEE/CPMT International Electronics Manufacturing Technology (IEMT) Symposium, Penang, Malaysia, 4-6 November 2008.

41. Liang, G.-F.; Lin, J.-T.; Hwang, S.-L.; Huang, F.-H.; Yenn, T.-C.; Hsu, C.-C. Evaluation and prediction of on-line maintenance workload in nuclear power plants. Hum. Factors Ergon. Manuf. 2009, 19, 64-77. [CrossRef]

42. Galar, D.; Stenstrom, C.; Parida, A.; Kumar, R.; Berges, L. Human factor in maintenance performance measurement. In Proceedings of the IEEE International Conference on Industrial Engineering and Engineering Management, Singapore, 6-9 December 2011.

43. Razak, I.H.A.; Kamaruddin, S.; Azid, I.A. Workforce competency model (WFCM): An empirical study in Malaysia of a model for maintenance workforce performance evaluation. Int. J. Product. Perform. Manag. 2011.

44. Wong, T.T.; Tong, S. An airworthiness SHELL model for aircraft maintenance. In Proceedings of the IEEE International Conference on Industrial Engineering and Engineering Management, Hong Kong, China, 10-13 December 2012.

45. Ab Samat, H.; Khoe, P.G.; Liau, W.S.; Tan, H.F.; Yap, W.Y.; Kamaruddin, S. Reduction of response time during machine breakdown: A case study in semiconductor industry. Int. J. Logist. Syst. Manag. 2013, 16, 167. [CrossRef]

46. Ighravwe, D.; Oke, S. A non-zero integer non-linear programming model for maintenance workforce sizing. Int. J. Prod. Econ. 2014, 150, 204-214. [CrossRef]

47. Marmier, F.; Varnier, C.; Zerhouni, N. Maintenance Activities Scheduling Under Competencies Constraints. In Proceedings of the International Conference on Service Systems and Service Management, ICSSSM '06, Troyes, France, 25-27 October 2006.

48. Sheikhalishahi, M.; Azadeh, A.; Pintelon, L.; Chemweno, P.; Ghaderi, S.F. Maintenance Scheduling Optimization in a Multiple Production Line Considering Human Error. Hum. Factors Ergon. Manuf. 2016, 26, 655-666. [CrossRef]

49. Sheikhalishahi, M.; Azadeh, A.; Pintelon, L. Dynamic maintenance planning approach by considering grouping strategy and human factors. Process. Saf. Environ. Prot. 2017, 107, 289-298. [CrossRef]

50. Bouzidi-Hassini, S.; Benbouzid-Sitayeb, F. Multi-agent based joint production and maintenance scheduling considering human resources. In Proceedings of the 5th International Conference on Modeling, Simulation and Applied Optimization (ICMSAO), Hammamet, Tunisia, 28-30 April 2013.

51. Touat, M.; Tayeb, F.B.-S.; Benhamou, B. An effective heuristic for the single-machine scheduling problem with flexible maintenance under human resource constraints. Procedia Comput. Sci. 2018, 126, 1395-1404. [CrossRef]

52. Blanco, A.; Díez, J.A.; López, D.; García, J.V.; Catalán, J.M.; García-Aracil, N. Human-centered design of an upper-limb exoskeleton for tedious maintenance tasks. Biosyst. Biorobot. 2019.

53. Bernard, F.; Zare, M.; Sagot, J.-C.; Paquin, R. Integration of human factors into the design process of helicopter maintainability. Hum. Factors Ergon. Manuf. 2019, 29, 350-360. [CrossRef]

54. Sheikhalishahi, M.; Eskandari, N.; Mashayekhi, A.; Azadeh, A. Multi-objective open shop scheduling by considering human error and preventive maintenance. Appl. Math. Model. 2019, 67, 573-587. [CrossRef]

55. Aromaa, S.; Väätänen, A.; Kaasinen, E.; Uimonen, M.; Siltanen, S. Human Factors and Ergonomics Evaluation of a Tablet Based Augmented Reality System in Maintenance Work. In ACM International Conference Proceeding Series; ACM: New York, NY, USA, 2018. 
56. Gerbaud, S.; Arnaldi, B. Scenario sharing in a collaborative virtual environment for training. In Proceedings of the ACM Symposium on Applied Computing—SAC '08, Fortaleza, Ceará, Brazil, 16-20 March 2008; ACM: New York, NY, USA, 2008.

57. Nappi, M.; Paolino, L.; Ricciardi, S.; Sebillo, M.; Vitiello, G. Advanced maintenance simulation by means of hand-based haptic in-terfaces. In Lecture Notes in Engineering and Computer Science; Including Subser. Lect. Notes Artif. Intell. Lect. Notes Bioinformatics; Springer: Berlin/Heidelberg, Germany, 2009.

58. Ziegler, J.; Pfeffer, J.; Urbas, L. A mobile system for industrial maintenance support based on embodied interaction. In Proceedings of the Proceedings of the 5th International Conference on Tangible, Embedded, and Embodied Interaction, TEI '11, Funchal, Madeira, Portugal, 23-26 January 2011.

59. De Crescenzio, F.; Fantini, M.; Persiani, F.; Di Stefano, L.; Azzari, P.; Salti, S. Augmented Reality for Aircraft Maintenance Training and Operations Support. IEEE Eng. Med. Boil. Mag. 2010, 31, 96-101. [CrossRef]

60. Gutiérrez, T.; Rodríguez, J.; Vélaz, Y.; Casado, S.; Suescun, A.; Sánchez, E.J. IMA-VR: A multimodal virtual training system for skills transfer in Industrial Maintenance and Assembly tasks. In Proceedings of the IEEE International Workshop on Robot and Human Interactive Communication, Viareggio, Italy, 13-15 September 2010.

61. Gofuku, A.; Matsuura, I.; Sugihara, T. Experimental investigation of information type in plant operation manuals. In Proceedings of the IECON Industrial Electronics Conference, Vienna, Austria, 10-13 November 2013.

62. Di Gironimo, G.; Mozzillo, R.; Tarallo, A. From virtual reality to web-based multimedia maintenance manuals. Int. J. Interact. Des. Manuf. 2013, 7, 183-190. [CrossRef]

63. Schroeder, H.; Friedewald, A.; Kahlefendt, C.; Lödding, H. Virtual Reality for the Training of Operators in Industry 4.0. In Proceedings of the IFIP International Conference on Advances in Production Management Systems, Hamburg, Germany, 3-7 September 2017; Springer: Cham, Switzerland, 2017.

64. Shamsuzzoha, A.; Toshev, R.; Tuan, V.V.; Kankaanpaa, T.; Helo, P. Digital factory-Virtual reality environments for industrial training and maintenance. Interact. Learn. Environ. 2019, 1-24. [CrossRef]

65. Nikolic, V.; Elzer, P.F.; Vetter, C. A monitor-based AR system as a support tool for industrial maintenance. IFAC Proc. Vol. IFAC-PapersOnline 2006, 39, 902-907. [CrossRef]

66. Álvarez, H.; Aguinaga, I.; Borro, D. Providing guidance for maintenance operations using automatic markerless augmented reality system. In Proceedings of the 10th IEEE International Symposium on Mixed and Augmented Reality, ISMAR 2011, Basel, Switzerland, 26-29 October 2011.

67. Espíndola, D.B.; Pereira, C.E.; Schneider, E.L.; Ventura, R.; Henriques, R.V.B. Improving Maintenance Operations Through Application of Mixed Reality Systems. IFAC Proc. Vol. IFAC-PapersOnline 2013, 46, 11-16. [CrossRef]

68. Ferrise, F.; Caruso, G.; Bordegoni, M. Multimodal training and tele-assistance systems for the maintenance of industrial products: This paper presents a multimodal and remote training system for improvement of maintenance quality in the case study of washing machine. Virtual Phys. Prototyp. 2013. [CrossRef]

69. Re, G.M.; Bordegoni, M. An augmented reality framework for supporting and monitoring operators during maintenance tasks. In Lecture Notes in Engineering and Computer Science; Including Subser. Lect. Notes Artif. Intell. Lect. Notes Bioinformatics; Springer: Berlin/Heidelberg, Germany, 2014.

70. Oliveira, A.; Caetano, N.; Botega, L.C.; de Araújo, R.B. A head-up display with augmented reality and Gamification for an E-maintenance system: Using interfaces and Gamification to motivate workers in procedural tasks. In Lecture Notes in Engineering and Computer Science; Including Subser. Lect. Notes Artif. Intell. Lect. Notes Bioinformatics; Springer: Berlin/Heidelberg, Germany, 2015.

71. Borsci, S.; Lawson, G.; Jha, B.; Burges, M.; Salanitri, D. Effectiveness of a multidevice 3D virtual environment application to train car service maintenance procedures. Virtual Real. 2016, 20, 41-55. [CrossRef]

72. Fiorentino, M.; Radkowski, R.; Boccaccio, A.; Uva, A.E. Magic mirror interface for augmented reality maintenance: An automotive case study. In Proceedings of the Workshop on Advanced Visual Interfaces AVI, Bari, Italy, 7-10 June 2016.

73. Jayaweera, M.; Wijesooriya, I.; Wijewardana, D.; De Silva, T.; Gamage, C. Demo abstract: Enhanced real-time machine inspection with mobile augmented reality for maintenance and repair. In Proceedings of the IEEE/ACM 2nd International Conference on Internet of Things Design and Implementation, IoTDI 2017 (part of CPS Week), Pittsburgh, PA, USA, 18-21 April 2017.

74. Mourtzis, D.; Vlachou, E.; Zogopoulos, V.; Fotini, X. Integrated Production and Maintenance Scheduling Through Machine Moni-toring and Augmented Reality: An Industry 4.0 Approach. IFIP Adv. Inf. Commun. Technol. 2017.

75. Masoni, R.; Ferrise, F.; Bordegoni, M.; Gattullo, M.; Uva, A.E.; Fiorentino, M.; Carrabba, E.; Di Donato, M. Supporting Remote Maintenance in Industry 4.0 through Augmented Reality. Procedia Manuf. 2017, 11, 1296-1302. [CrossRef]

76. Momin, G.; Panchal, R.; Liu, D.; Perera, S. Case Study: Enhancing Human Reliability with Artificial Intelligence and Augmented Reality Tools for Nuclear Maintenance. In Proceedings of the ASME Power Conference, Lake Buena Vista, FL, USA, 24-28 June 2018; American Society of Mechanical Engineers: New York, NY, USA, 2018.

77. Uva, A.E.; Gattullo, M.; Manghisi, V.M.; Spagnulo, D.; Cascella, G.L.; Fiorentino, M. Evaluating the effectiveness of spatial aug-mented reality in smart manufacturing: A solution for manual working stations. Int. J. Adv. Manuf. Technol. 2018. [CrossRef]

78. Lorenz, M.; Knopp, S.; Klimant, P. Industrial Augmented Reality: Requirements for an Augmented Reality Maintenance Worker Support System. In Proceedings of the IEEE International Symposium on Mixed and Augmented Reality, ISMAR-Adjunct, Munich, Germany, 16-20 October 2018; IEEE: Piscatawy, NJ, USA, 2019. 
79. Zhao, F.; Liu, X.; Peng, R. Inspection-Based Policy Considering Human Errors for Three-Stage Delay Time Degradation Systems. J. Shanghai Jiaotong Univ. 2018, 23, 702-706. [CrossRef]

80. Hsia, T.-C.; Chen, H.-T.; Chen, W.-H. Measuring the readability performance (RP) of aircraft maintenance technical orders by fuzzy MCDM method and RP index. Qual. Quant. 2008, 42, 795-807. [CrossRef]

81. Wu, H.-Y.; Chen, J.-K.; Chen, I.-S. Performance evaluation of aircraft maintenance staff using a fuzzy MCDM approach. Int. J. Innov. Comput. Inf. Control 2012.

82. Lahiani, N.; El Mhamedi, A.; Hani, Y.; Triki, A. A novel improving method of industrial performance based on human resources management. IFAC-PapersOnLine 2016, 49, 262-267. [CrossRef]

83. Mahatmavidya, P.A.; Soesanto, R.P.; Kurniawati, A.; Andrawina, L. Characteristic and Competency Measurement Instrument Development for Maintenance Staff of Mechanical Expertise with SECI Method: A Case of Manufacturing Company. In IOP Conference Series: Materials Science and Engineering; IOP Publishing Ltd.: Bristol, UK, 2018; Volume 319.

84. Sun, R.; Zhang, Y.; Liu, Z.; Li, K. Task-Load Evaluation Method for Maintenance Personnel Based on the JACK Simulation. In Lecture Notes in Engineering and Computer Science; Including Subser. Lect. Notes Artif. Intell. Lect. Notes Bioinformatics; Springer: Berlin/Heidelberg, Germany, 2018.

85. Zhang, R.-Q.; Yang, J.-L. Association Rules Based Research on Man-Made Mistakes in Aviation Maintenance: A Case Study. In Proceedings of the ISDA 2006: Sixth International Conference on Intelligent Systems Design and Applications, Jinan, China, 16-18 October 2006.

86. Wang, L.; Sun, R.; Yang, Z. Analysis and evaluation of human factors in aviation maintenance based on fuzzy and AHP method. In Proceedings of the IEEM 2009-IEEE International Conference on Industrial Engineering and Engineering Management, Hong Kong, China, 8-11 December 2009.

87. Emami-Mehrgani, B.; Neumann, W.P.; Nadeau, S.; Bazrafshan, M.; Neumann, P. Considering human error in optimizing production and corrective and preventive maintenance policies for manufacturing systems. Appl. Math. Model. 2016, 40, 2056-2074. [CrossRef]

88. Cabahug, R.R.; Edwards, D.J.; Nicholas, J. Classifying plant operator maintenance proficiency: Examining personal variables. Build. Res. Inf. 2004, 32, 119-127. [CrossRef]

89. Heo, G.; Park, J. A framework for evaluating the effects of maintenance-related human errors in nuclear power plants. Reliab. Eng. Syst. Saf. 2010, 95, 797-805. [CrossRef]

90. Bohlouli, M.; Ansari, F.; Fathi, M. Design and realization of competence profiling tool for effective selection of professionals in maintenance management. In Proceedings of the IEEE International Conference on Systems, Man, and Cybernetics (SMC), Seoul, Korea, 14-17 October 2012.

91. Schmuntzsch, U.; Feldhaus, L.H. The Warning Glove: Wearable Computing Technology for Maintenance Assistance in IPS2. IFAC Proc. Vol. IFAC-PapersOnline 2013, 46, 70-75. [CrossRef]

92. Oliveira, A.; Araujo, R.; Jardine, A. Human-centered interfaces for situation awareness in maintenance. In Lecture Notes in Engineering and Computer Science; Including Subser. Lect. Notes Artif. Intell. Lect. Notes Bioinformatics; Springer: Berlin/Heidelberg, Germany, 2014.

93. Zheng, X.S.; Foucault, C.; Da Silva, P.M.; Dasari, S.; Yang, T.; Goose, S. Eye-wearable technology for machine maintenance: Effects of display position and hands-free operation. In Proceedings of the Conference on Human Factors in Computing Systems, Seoul, Korea, 18-23 April 2015.

94. Guest, D.E. Human resource management and performance: A review and research agenda. Int. J. Hum. Resour. Manag. 1997, 8, 263-276. [CrossRef]

95. Muñoz, J.; Mahiques, A.; Solanes, X.; Martí, J.E.; Gracia, A.; Tornero, L. Mixed reality-based user interface for quality control inspection of car body surfaces. J. Manuf. Syst. 2019, 53, 75-92. [CrossRef]

96. Ruppert, T.; Jaskó, S.; Holczinger, T.; Abonyi, J. Enabling technologies for operator 4.0: A survey. Appl. Sci. 2018, 8, 1650. [CrossRef]

97. Romero, D.; Noran, O.; Stahre, J.; Bernus, P.; Fast-Berglund, Å. Towards a Human-Centred Reference Architecture for Next Generation Balanced Automation Systems: Human-Automation Symbiosis BT. In Proceedings of the IFIP International Conference on Advances in Production Management Systems, Iguassu Falls, Brazil, 3-7 September 2015; pp. 556-566.

98. Longo, F.; Nicoletti, L.; Padovano, A. Smart operators in industry 4.0: A human-centered approach to enhance operators' capabilities and competencies within the new smart factory context. Comput. Ind. Eng. 2017, 113, 144-159. [CrossRef]

99. Zolotová, J.; Papcun, I.; Kajáti, P.; Miškuf, E.; Mocnej, M. Smart and cognitive solutions for operator 4.0: Laboratory H-CPPS case studies. Comput. Ind. Eng. 2018, 139, 105471. [CrossRef] 